\title{
Title: Seasonal dispersal of fjord meltwaters as an important source of iron to coastal Antarctic phytoplankton
}

Kiefer Forsch, Scripps Institution of Oceanography, University of California San Diego, La Jolla, 92037, USA

kforsch@ucsd.edu

5 Lisa Hahn-Woernle, Department of Oceanography, University of Hawai i, Manoa, 96822, USA, lisahw@hawaii.edu Robert Sherrell, Department of Marine and Coastal Sciences, Rutgers University, New Brunswick, 08901, USA, sherrell@marine.rutgers.edu

Joe Roccanova, Department of Marine and Coastal Sciences, Rutgers University, New Brunswick, 08901, USA, roccanova@marine.rutgers.edu

10 Kaixan Bu, Department of Marine and Coastal Sciences, Rutgers University, New Brunswick, 08901, USA, bu@marine.rutgers.edu

David Burdige, Department of Ocean \& Earth Sciences, Old Dominion University, Norfolk, 23529, USA, dburdige@odu.edu

Maria Vernet, Scripps Institution of Oceanography, University of California San Diego, La Jolla, 92037, USA,

15 mvernet@ucsd.edu

Katherine A. Barbeau, Scripps Institution of Oceanography, University of California San Diego, La Jolla, 92037, USA, kbarbeau@ucsd.edu

Correspondence to: Kiefer O. Forsch (kforsch@ucsd.edu)

This paper is a non-peer reviewed preprint submitted to EarthArXiv.

20 
40 Abstract. Glacial meltwater from the western Antarctic Ice Sheet is hypothesized to be an important source of cryospheric iron, fertilizing the Southern Ocean, yet its trace metal composition and factors which control its dispersal remain poorly constrained. Here we characterize meltwater iron sources in a heavily glaciated western Antarctic Peninsula (WAP) fjord. Using dissolved and particulate ratios of manganese-to-iron of meltwaters, porewaters, and seawater, we show glacial melt and subglacial plumes contribute to the seasonal cycle of bioavailable iron within a relatively undisturbed fjord. Ligand sources

45 associated with the phytoplankton bloom and glaciers bind to iron, facilitating the solubilization of particulate iron downstream. Using a numerical model, we show subsurface subglacial plumes, enriched in labile particulate trace metals, derived from a chemically-modified crustal source, can supply the surface, and that prolonged katabatic wind events enhance export of meltwater out of the fjord. Thus, we identify an important atmosphere-ice-ocean coupling intimately tied to coastal iron biogeochemistry and primary productivity along the WAP.

\section{Introduction}

Warm temperatures are accelerating glacial retreat and increasing meltwater discharge, rapidly changing the cryosphere (Rignot et al., 2013; Mouginot et al., 2019). Ranging from diffuse flows to waterfalls and streams, cryospheric meltwaters deliver dissolved and particulate material, altering coastal ocean biogeochemistry. Meltwater enters the ocean through surface runoff, direct melting of glacial ice (including icebergs), and discharge from beneath glaciers, carrying with it iron (Fe) and

55 other trace metals weathered from continental crust. In the surface ocean, the delivery of new Fe is critical for the growth of phytoplankton; and when enhanced, naturally or artificially, carbon is sequestered by the biological pump (Boyd et al. 2019). However, direct measurements of $\mathrm{Fe}$ in heavily glaciated fjords reveal up to $90-99 \%$ of dissolved $\mathrm{Fe}(\mathrm{dFe}$ ) originating from glaciers is removed upon mixing with seawater due to estuarine-type removal processes, including: precipitation of insoluble oxyhydroxides, adsorption to the surfaces of existing particles, and aggregation of colloids and particles (Boyle, Edmond and

60 Sholkovitz, 1977; Schroth et al., 2014). Together, these processes are known as scavenging and constitute a major control on the distribution of $\mathrm{Fe}$ in the ocean by converting soluble forms of Fe into colloidal aggregates and particles (Wu et al. 2001). Constraints on the flux of newly delivered glacial Fe that escapes this sink and is transported across continental shelves will enable better predictions of open ocean primary production and carbon sequestration, especially in places where Fe is a limiting nutrient.

65 Evidence for Fe delivery from the cryosphere is historically based on geochemical analysis of endmember glacial discharge (Hawkings et al. 2014; Raiswell and Canfield 2012; Hodson et al. 2017; Hawkings et al. 2020), and discrete sampling of glacial ice (e.g. Hopwood et al. 2018) and seawater adjacent to marine-terminating glaciers and ice sheets (Hopwood et al. 2016; 
Annett et al. 2015; Gerringa et al. 2015; Alderkamp et al. 2012; Sherrell et al. 2018). Trace metal studies at the ice-ocean interface have previously been conducted in fjords experiencing intense seasonal melt, such as in Alaska and Greenland

70 (Schroth et al. 2014; Hopwood et al. 2016; Zhang et al. 2015). These temperate and high Arctic coastal waters experience large freshwater and sediment fluxes as a result of increased glacial discharge, which in turn create extreme physical and geochemical gradients. Ultimately, such dramatic changes in turbidity disturb local primary production due to decreased light availability within the water column and reduced macronutrient supply (Meire et al., 2017). Even with high particulate and dissolved Fe contents, meltwaters from these fjords do not directly feed into offshore waters without significant scavenging, 75 mixing and dilution (Hopwood et al. 2015), bringing into question the ability of glacial dFe to fertilize the surrounding ocean. Although less well-studied than their Arctic counterparts, Antarctic fjords are also locations of intense seasonal blooms with comparable primary production to the adjacent continental shelves, and high sequestration efficiencies of organic carbon (Vernet et al. 2008; Grange and Smith 2013; Taylor, DeMaster, and Burdige 2020). Along the western Antarctic Peninsula (WAP), 674 marine-terminating glaciers drain into the coastal ocean, primarily in fjords (Cook et al., 2016). The vast majority

80 of these marine-terminating glaciers are retreating due to intrusions of warm deep water from the shelf, but many still remain cold-based (that is, ocean temperatures are too cold to ablate the glacier terminus), particularly in the northern WAP where Weddell Water from the eastern side mixes with the Bransfield Strait (Pritchard and Vaughan, 2007; Cook et al., 2016). These glaciers are thought to have relatively small subglacial meltwater discharge, with suspended sediment signatures that spread laterally in the coastal ocean (Domack and Ishman, 1993; Domack and Williams, 2011). This makes cold glacio-marine

85 Antarctic fjords unique locations for sampling subglacial discharge with minimal alteration.

Subglacial environments distinguish themselves from other cryospheric sources of Fe to the oceanic euphotic zone. Within the subglacial cavity, anoxia develops due to enhanced microbial respiration processes, high weathering rates, and limited diffusion of oxygen and exchange with the coastal ocean (Mikucki et al., 2009). The result is increased solubility of iron as $\mathrm{Fe}(\mathrm{II})$, and other redox sensitive elements, such as manganese (Mn). Meltwater discharge from beneath marine-terminating

90 glaciers enters the ocean in the subsurface but may be mixed into the surface due to its positive buoyancy relative to seawater. Enhanced vertical shear occurs episodically in the Antarctic coastal ocean as cooled dense parcels of air accelerate down ice sheets, generating the strongest winds on Earth $\left(>30 \mathrm{~m} \mathrm{~s}^{-1}\right)$, near the coast. These episodic wind events, called katabatic winds, could also be important for enhancing the supply of subsurface meltwaters to the surface (Jackson, Straneo and Sutherland, 2014; Lundesgaard et al., 2019). The subglacial meltwater source represents a large uncertainty in the supply of cryospheric

95 Fe to the ocean given the challenge of acquiring samples directly or with minimal alteration, particularly in Arctic environments with intense seasonal melt flows and associated sediment turbidity (Straneo and Cenedese, 2015).

We present trace metal results from two expeditions (December 2015 and April 2016) to Andvord Bay, a cold glacio-marine fjord located mid-latitude along the WAP. This study is part of the FjordEco project which assessed the ecosystem function and seasonality of Andvord Bay (Pan et al. 2019; Pan et al. 2020; Ziegler et al. 2020; Eidam et al. 2019; Lundesgaard et al. 100 2020, 2019; Hahn-Woernle et al. 2020). The WAP is host to the most extensive collection of glaciomarine fjords on the 
Antarctic continent, and in the midst of large-scale changes to the western Antarctic Ice Sheet, we present a detailed picture of fjord Fe biogeochemistry and seasonality prior to significant glacier retreat, for which few ocean measurements exist.

\section{Methods}

\subsection{Oceanographic setting and sampling}

105 Andvord Bay is a glacio-marine fjord located mid-latitude along the west Antarctic Peninsula (WAP). This site was chosen as prior studies have identified it as a productivity "hotspot", its proximity to long-standing ecological research programs (Pal LTER), and as a region of converging deep water masses with distinct physical properties (relatively warm modified Upper Circumpolar Deep Water, cold Weddell Water). Bordering Andvord Bay are 11 marine-terminating glaciers (Fig. 1) with Moser and Bagshawe glaciers responsible for the majority of the solid ice flux. These glaciers are cold-based resulting in weak

110 meltwater signatures within the fjord. On December 11, 2015 a strong katabatic wind event, with peak along-fjord velocities of $16 \mathrm{~m} \mathrm{~s}^{-1}$, was observed and lasted for 2 days. Atmospheric observations by two automatic weather stations (Neko Harbor, Useful Island) recorded episodes of high velocity katabatic winds between field seasons, showing these are common events in this study region. Observations and sampling of Andvord Bay were conducted during two cruises as part of the FjordEco program between 27 November and 22 December 2015 (late-Spring), during the LMG15-10 cruise on the R/V Laurence M.

115 Gould and again between 4 April and 26 April (Fall), during the NBP16-03 cruise on the R/V Nathaniel B. Palmer.

A total of 18 stations per season were sampled for Fe geochemical variables using acid-cleaned 12 L GO-Flo bottles (General Oceanics) suspended in series on a clean hydroline (Amsteel) and triggered with acid-cleaned Teflon messengers designed by Ken Bruland (UC Santa Cruz). This sampling effort coincided with concurrent CTD stations. Once on board, GO-Flo bottle tops and bottoms were covered with plastic and placed on a wooden rack located within the trace metal clean shipboard plastic "bubble", which was positively-pressurized with HEPA-filtered air. Samples for dFe analysis were pressure-filtered (high purity N2 gas) directly from GO-Flo bottles through $0.2 \mu \mathrm{m}$ Acropak 200 capsule filters (VWR International), into low-density polyethylene bottles (Nalgene) and acidified to $\mathrm{pH} 1.7$ to 1.8 using $\mathrm{HCl}$ (Optima grade, Fisher Scientific). Samples for Febinding ligands were similarly filtered in-line but collected in fluorinated high-density polyethylene (Nalgene) bottles, unacidified, and frozen at $-20^{\circ} \mathrm{C}$ until laboratory analysis back on land. In brief, sample bottles were soaked in a soap detergent

125 overnight with heat applied $\left(60^{\circ} \mathrm{C}\right)$, followed by a one-week soak in $3 \mathrm{~N} \mathrm{HNO}_{3}$ (trace metal grade) at room temperature, and finally, a one-week soak in a $3 \mathrm{~N} \mathrm{HCl}$ (trace metal grade) bath at room temperature. Rinsing with ultrapure MilliQ water occurred after each step. These sampling methods were conducted following established trace-metal clean methods to the standards of the GEOTRACES program to avoid metal contamination. In addition to the filtered samples, unfiltered seawater was sampled directly from the GO-Flo bottles and acidified to $\mathrm{pH} 1.8$ and stored for $>6$ months and filtered prior to analysis in order to determine total dissolvable Fe (TDFe). Labile particulate $\mathrm{Fe}(\mathrm{LpFe})$ is calculated as the difference between TDFe and dFe. Prior to analysis in the laboratory, these unfiltered acidified samples were vacuum filtered using acid-cleaned $0.4 \mu \mathrm{m}$ polycarbonate (PC) filters in a Teflon filtration apparatus. Particulate samples were collected on $0.4 \mu \mathrm{m}$ PC filters and stored 
at $-20^{\circ} \mathrm{C}$ until complete digestion by $\mathrm{HNO}_{3} / \mathrm{HF}$ mixture. The digestion method employed is described in Planquette and Sherrell, 2013 and Fitzsimmons et al., 2017 and was applied to the US GEOTRACES GP16 total particulate trace metal sample

135 set (Fitzsimmons et al., 2017).

Acute attention to cleanliness was applied when sampling frozen freshwater samples (snow, sea ice, icebergs, "dip" samples) during small boat deployments in the fjord and while on shore. On land, undisturbed snow samples, away from human and penguin traffic, were scooped in to clean $2 \mathrm{~L}$ FLPE bottles (Nalgene) and stored in a $-4^{\circ} \mathrm{C}$ freezer once back on the ship. Floating icebergs and sea ice were sampled using a clean stainless-steel pickaxe (for icebergs) and rust-free stainless-steel

140 screwdriver and plastic mallet (for sea ice) for chiseling pieces of ice. Each piece of ice was collected above freeboard (sea surface), to reduce the chance the ice was altered by seawater and rinsed with MilliQ prior to placing into acid-cleaned 2 gallon Ziploc polyethylene bags and storing at $-4^{\circ} \mathrm{C}$ until sample processing. A surface "dip" sample was collected by slowly (engine idled) approaching the target piece of floating ice from downwind, limiting the chance of engine exhaust contamination, and fully submerging a 2 L FLPE bottle with an arm-length polyethylene glove. Prior to filtration, ice samples were removed from

145 the freezer and left to melt at ambient shipboard temperatures. Once completely melted, a small incision was made on the Ziploc bags using a clean stainless-steel razor and contents poured into the Teflon filtration manifold or directly into sample bottles, thus collecting samples for dissolved, total dissolvable and particulate trace metal fractions.

\subsection{Trace metal concentrations}

Stored acidified filtered seawater samples were analyzed for Fe using flow injection with chemiluminescence methods 150 described by Lohan et al. (Lohan, Aguilar-Islas and Bruland, 2006). Dissolved Fe in the samples was oxidized to iron(III) for $1 \mathrm{~h}$ with $10 \mathrm{mM}$ Q- $\mathrm{H}_{2} \mathrm{O}_{2}$, buffered in-line with ammonium acetate to $\mathrm{pH} \sim 3.5$ and selectively pre-concentrated on a chelating column packed with a resin (Toyopearl ${ }^{\circledR}$ AF-Chelate-650M). Dissolved Fe was eluted from the column using $0.14 \mathrm{M} \mathrm{HCl}$ (Optima grade, Fisher Scientific) and the chemiluminescence was recorded by a photomultiplier tube (PMT, Hamamatsu Photonics). The manifold was modified based on Lohan et al. 2006. Standardization of Fe was carried out with a matrix-

155 matched standard curve $\left(0,0.4,0.8,3.2,10 \mathrm{nmol} \mathrm{kg}{ }^{-1}\right.$ added high purity Fe metal ICP spectrometry standard in $\left.2 \% \mathrm{HNO}_{3}\right)$ using low-Fe open ocean seawater. Standards were treated identically to samples. Accuracy was assessed by repeated measurements of GEOTRACES coastal and Pacific Ocean reference seawater samples. Our measurements of GSC gave Fe = $1.391 \pm 0.115(n=19$, over a three-month period, consensus $1.535 \pm 0.115)$. Our measurements of GSP gave Fe $=0.164 \pm 0.024$ ( $n=8$, over a one-month period, consensus $0.155 \pm 0.045$ ). Consensus values are from the most recent July 2019 compilation

160 (geotraces.org). Precision, determined by replicated analyses of an in-house large-volume reference seawater sample within each analytical session, was typically $\pm 5 \%$ or better. For the duration of these analyses, the average LOD (defined as $3 x$ the standard deviation of the blank) was $0.036(n=10)$.

A subset of the seawater samples and all freshwater samples were run for $\mathrm{Fe}$ and $\mathrm{Mn}$ using isotope dilution-inductively coupled plasma mass spectrometry (ICP-MS) methods based on Lagerström et al. (2013) and similar to those described in Annett et 
al. (2017). Briefly, $10 \mathrm{~mL}$ aliquots of seawater samples were extracted using a commercially available automated SeaFAST pico system (Elemental Scientific, Inc.) after online buffering to $\mathrm{pH}$ approximately 6.5 using ammonium acetate buffer, achieving a 25-fold pre-concentration after column elution in $0.4 \mathrm{~mL} \mathrm{10 \% (v/v)} \mathrm{ultrapure} \mathrm{nitric} \mathrm{acid} \mathrm{(Optima} \mathrm{grade,} \mathrm{Fisher}$ Scientific)(Lagerström et al., 2013). Isotope dilution was used to standardize Fe, while Mn was standardized using external matrix-matched standards treated identically to samples. The analysis of the concentrate was performed on an Element 2 sector-

170 field ICP-MS (Thermo Fisher Scientific). Accuracy and precision $( \pm 3 \%, 1 \mathrm{SD}$, for Fe and Mn) was assessed by repeated measurements of in-house large-volume reference seawater samples within each analytical session. Blanks averaged 51 pmol $\mathrm{kg}^{-1}$ for $\mathrm{Fe}\left(n=59 ; \mathrm{LOD}=48 \mathrm{pmol} \mathrm{kg}{ }^{-1}\right)$ and $4 \mathrm{pmol} \mathrm{\textrm {kg } ^ { - 1 }}$ for $\mathrm{Mn}\left(n=69 ; \mathrm{LOD}=4 \mathrm{pmol} \mathrm{kg}^{-1}\right)$ for all analytical runs. A comparison of the seawater analysis methods employed here is shown in SI Fig. 1. In general, there is good agreement (average $11 \%$ and $6 \%$ difference late-Spring and Fall, respectively) between the chemiluminescence and ICP-MS methods, comparable

175 to the uncertainty of GEOTRACES consensus values from the intercalibration of 13 trace metal laboratories (for Fe, RSD 10\%, https://www.geotraces.org/standards-and-reference-materials/). Particle digests were analyzed using direct-injection methods using external standards for the quantification of particulate $\mathrm{Fe}, \mathrm{Mn}$, aluminum (Al), and titanium (Ti) concentrations (Annett et al., 2017).

\subsection{Sediment cores and diffusive flux}

180 See Taylor et al. (2020) for a complete account of coring efforts and Komada et al. (2016) for a description of the pore water sampling procedures. Porewater $\mathrm{dFe}$ and $\mathrm{dMn}$ was determined colorimetrically using the ferrozine and formaldoxime techniques, respectively (Armstrong, Lyons and Gaudette, 1979; Burdige and Komada, 2020). For dFe, hydroxylamine-HCl ( $0.2 \%$ final concentration) was added to the samples before analysis, to reduce any dissolved Fe(III) in the samples to Fe(II). For dMn, a solution of hydroxylamine solution was added to an acidified ( $\mathrm{pH} \sim 1-2)$ sample, and an EDTA solution was added

185 to remove interference from a colored Fe complex. Porewater oxygen concentrations were measured using a polarographic microelectrode (Brendel and Luther 1995; Luther et al. 1998, 2008). A sequential extraction technique (Poulton and Canfield, 2005; Goldberg et al., 2012) was used to determine sediment Fe speciation for the following fractions: Fe (highly reactive, poorly crystalline iron oxides), $\mathrm{Fe}_{\mathrm{mag}}$ (magnetite), $\mathrm{Fe}_{\mathrm{prs}}$ ( $\mathrm{Fe}$ in poorly reactive sheet silicates), $\mathrm{Fe}_{\mathrm{T}}$ (total sediment $\mathrm{Fe}$ ), $\mathrm{Fe}_{\mathrm{pyr}}(\mathrm{Fe}$ in pyrite), and finally $\mathrm{Fe}_{\mathrm{U}}$ (unreactive pool under all treatments $=\mathrm{Fe}_{\mathrm{T}}-\left(\mathrm{Fe}_{\mathrm{ox}}+\mathrm{Fe}_{\mathrm{mag}}+\mathrm{Fe}_{\mathrm{prs}}+\mathrm{Fe}_{\mathrm{pyr}}\right)$ ). All extracts were analyzed

190 for Fe by flame Atomic Absorption Spectrometry (for details see Burdige and Komada 2020).

In this study, we investigate the potential for efflux of dissolved trace metals as a source to the overlying water column. Using equation 1, we can estimate the approximate sediment diffusive flux $\left(\mathrm{J}_{\mathrm{sed}}\right)$ for dissolved porewater species.

$J_{\text {sed }}=-\phi D_{\text {sed }} \frac{d C}{d z}$

In this equation, $\phi$ is the porosity of the sediments, and was found to be on average 0.9 near the sediment surface. Porewater analyses of soluble Fe and $\mathrm{Mn}$ in the Outer Basin $(\mathrm{OB})$ cores reveal high variability in the top-of-core gradient $\left(\frac{d C}{d z}\right)$ in porewater 
Fe and Mn (SI Fig. 2). An average of two cores gives a gradient of $\sim 21.9 \mu \mathrm{M} \mathrm{cm}^{-1}$ soluble Fe and $\sim 3.6 \mu \mathrm{M} \mathrm{cm}^{-1}$ soluble Mn. Assuming a diffusion coefficient for $\mathrm{Fe}$ and $\mathrm{Mn}$ in free solution for seawater ( $\mathrm{Dsw}_{\mathrm{sw}}$ ) at $0^{\circ} \mathrm{C}$ to be $3.15 \times 10^{-10} \mathrm{~m}^{2} \mathrm{~s}^{-1}$ for $\mathrm{Fe}$ (II) and $3.02 \times 10^{-10} \mathrm{~m}^{2} \mathrm{~s}^{-1}$ for $\mathrm{Mn}(\mathrm{II})$, we can then estimate the diffusion coefficient in the sediments $\left(\mathrm{D}_{\mathrm{sed}}\right)$ by the following relationship (van Duren and Middelburg, 2001; Halbach et al., 2019):

$D_{\text {sed }}=\frac{D_{S W}}{1-2 \ln \phi}$

\subsection{Iron-binding ligands}

A subset of seawater samples was analyzed for dFe-binding ligands using single analytical window methods. The methods applied here are described extensively in Buck et al., 2016 (Buck et al., 2018). Briefly, natural seawater samples were titrated with $\mathrm{dFe}(0-35 \mathrm{nM})$ in order to fully saturate the natural ligands. Following a 2 hour equilibration with the added Fe, a wellcharacterized ligand (salicylaldoxime, SA) was added to compete with natural dFe-binding ligands. The concentration of SA used in this study to examine ligands was $25.0 \mu \mathrm{mol} \mathrm{L}^{-1}\left(\alpha_{F e(S A)_{x}}=115\right)$. After at least 15 minutes of equilibration, the $\mathrm{Fe}(\mathrm{SA})_{\mathrm{x}}$ electroactive complex was measured using adsorptive cathodic stripping voltammetry (ACSV) on a hanging mercury drop electrode (BioAnalytical Systems, Incorporated). Peak heights were measured using ECDSOFT and sensitivity was optimized in ProMCC (Omanović, Garnier and Pižeta, 2015). A combination of traditional linearization techniques was used to determine

210 the concentrations and strengths of natural ligands within the seawater sample using ProMCC (Omanović, Garnier, and Pižeta 2015). The uncertainty on modelled complexation parameters was optimized using single or multiple ligand fitting. These methods were applied successfully to the GEOTRACES speciation data sets (Buck, Sohst and Sedwick, 2015; Buck et al., 2018).

We calculate the capacity for the free ligand pool to bind Fe at equilibrium (Fitzsimmons et al., 2015), or $\alpha_{\mathrm{FeL}}$ ', defined as:

$215 \alpha_{F e L^{\prime}}=1+([e L] \times K)$,

where $e L$ is the difference between the total ligand concentration $\left(L_{t}\right)$ and the dFe concentration, and $K$ is the conditional stability constant.

\subsection{Numerical model simulations}

Based on Hahn-Woernle et al. 2020, the ocean in the Andvord Bay region is modelled with the primitive-equation, finitedifference Regional Ocean Model System (ROMS, Haidvogel et al. 2008). The grid has a horizontal resolution of $\sim 350 \mathrm{~m}$ and a terrain-following vertical coordinate system with 25 depth layers. Due to the changing terrain, the fixed number of layers, and surface intensified resolution, the maximum thickness for deeper layers is $84.6 \mathrm{~m}$ and the minimum thickness for surface layers is $0.5 \mathrm{~m}$ (to better resolve e.g. the surface currents). The domain has 3 open boundaries: the western end of Bismark Strait, a passage to the continental shelf in the northwest, and along Gerlache Strait to the northeast (Fig. 1). Boundary and initial conditions were derived from CTD and ADCP observations. The model is forced with tidal and meteorological data 
(from TPXO8 Egbert and Erofeeva 2002 [updated] and RACMO van Wessem et al. 2014, respectively) and run from November 2015 for 5 months. After one month, the transient effects, based on dynamics and thermodynamics, were found to no longer be present, and the system was consistent. Only the final four sea-ice free months were analyzed (December through March). Processes like melting of icebergs and floating sea ice are not directly modelled, therefore such local freshwater sources are captured in a surface intensified meltwater input applied along the glacial boundaries. These new freshwater sources include also surface runoff and local melt of glacial ice, while precipitation and snowfall are represented in the meteorological forcing. The applied volume transport of meltwater is a rough estimate based on few modelled results and observed data and results in an intensified meltwater input at the glacial fronts (for further details see Hahn-Woernle et al. 2020). To represent the seasonal cycle of temperature induced melting the volume flux of inflowing meltwater follows a bellshaped temporal distribution peaking at the end of January.

We use this model to identify the potential supply pathways and export of three Fe-rich sources in Andvord Bay: surface glacial meltwater, subsurface subglacial plume, and deep water masses located within the inner basin. For this purpose, we designed three model experiments with dyes to track potential iron pathways: one, to track the current seasonal input of meltwater from glaciers in Andvord Bay contains a dye (surface meltwater dye experiment) released along the glacial fronts

240 in the inner fjord at 0-50 $\mathrm{m}$ depth (Fig. 1); and two additional experiments involving water masses in front of Bagshawe Glacier

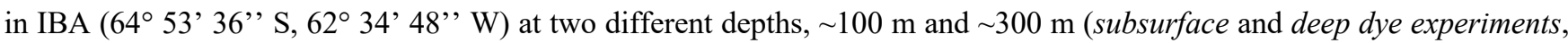
respectively). Due to the model geometry, the actual mean depths the subsurface and deep dyes were released were 107 (94$102 \mathrm{~m}$ ) and $314 \mathrm{~m}$ (290-342 m), respectively. Covering two grid cells each (with different thickness), the subsurface and deep dyes had initial volumes of $5 \times 10^{6}$ and $11.3 \times 10^{6} \mathrm{~m}^{3}$, respectively. It follows from the experiment setup that the meltwater dye has a continuous source while the total amount of the other two dyes is a constant as long as they do not leave through the open boundaries of the model domain.

\section{Results}

We present seasonal results of $\mathrm{Fe}$ and $\mathrm{Mn}$ concentration and speciation, including a first assessment of Fe-binding ligands in a cold-based Antarctic fjord. Based on sediment cores collected in the fjord, we also present porewater Fe speciation and

250 estimate the sedimentary efflux of dFe and dMn. Finally, the dispersal of Fe-rich sources is modelled to identify pathways for Fe supply and later, discuss important dynamics contributing to their dispersal.

\subsection{Seasonality and hydrography in Andvord Bay}

In Andvord Bay (Fig. 1), seasonal changes in phytoplankton biomass were documented, as indicated by the proxy Chlorophylla, which shows a 10-fold concentration decrease across all taxonomic classes between the late-spring and fall cruises (Pan et al., 2020). Associated with these changes in primary production, depletion of the surface macronutrients nitrate $(\mathrm{N})$ and silicic acid (Si) were observed (Ekern, 2017). Increased Si concentrations within the inner fjord could be driven by sedimentary 
processes, or weathering of the bedrock by contact with the 11 marine-terminating glaciers feeding into Andvord Bay (Hawkings et al., 2018; Ng et al., 2020). Surface stocks of macronutrients were never exhausted (Fig. 2). The phytoplankton community was dominated by small size classes, with very few large diatoms (Pan et al., 2020). The microplankton class was

260 sparingly present in the Fall, however, benthic cameras captured a large sedimentation event of marine aggregates indicative of a large diatom bloom in late-January. The export of biogenic particles from the surface also showed a distinct seasonality indicated by increased Chlorophyll-a pigment content in seafloor sediment cores (Ziegler et al., 2020), as well as higher respiration rates from chamber incubation experiments in the Fall compared to Spring (data not shown), although no indication of sulfate reduction was observed in sediment box and Kasten cores, suggesting that oxygen, nitrate, and metal oxides were

265 sufficient to oxidize organic matter within the upper sediments (C. Smith pers. comm.).

Derived meltwater fractions (MWf, Fig. 2), based on salinity and oxygen isotopes of seawater, ranged from $0.75-2 \%$ in lateSpring, and 0.5-2.5\% in the Fall (Pan et al. 2019). The fjord also exhibited a gradient in meltwater content, with highest MWf at the glacier terminus. We estimate an approximate meltwater input of $23600 \mathrm{~m}^{3} \mathrm{~d}^{-1}$ in order to account for the observed changes in oxygen isotope ratios in the surface layer. This estimate is within the derived estimates of surface meltwater flux generated by warm atmospheric temperatures $\left(1.4 \times 10^{4}\right.$ to $1.2 \times 10^{5} \mathrm{~m}^{3} \mathrm{~d}^{-1}$; Lundesgaard et al. 2020). MWf is strongly correlated with phytoplankton abundance within Andvord Bay; for a detailed discussion see Pan et al., (2019). We find glacial meltwater impacts phytoplankton within the fjord, but the geographical influence of meltwater can extend across the shelf, hundreds of kilometers from the coastal inputs (Dierssen, Smith and Vernet, 2002; Meredith et al., 2017).

Physical properties measured in the study region showed the dominant water masses in the fjord were Antarctic Surface Water

275 (cold fresh) and Bransfield Strait water (cold and salty) (Lundesgaard et al., 2020). However, during late-Spring, greater influence of modified Upper Circumpolar Deep Water was observed outside of the fjord, indicated by its distinctly higher temperature at depth, but is constrained from entering the fjord due to a shallow sill near the fjord mouth (Fig. 2). Optical measurements recorded a change in the particle concentration and assemblage between the two cruises. Profiles of beam attenuation coefficient and particulate backscattering coefficient showed strong seasonality (see Fig. 4 and discussion in Pan

280 et al., 2019). Pan et al. interpreted these optical signatures in the upper water column as a change from a surface biogenicdominated assemblage in late-Spring to a subsurface lithogenic-dominated assemblage in the Fall, composed of fine suspended particles contained within plumes. An important feature observed within the fjord was a subsurface neutrally-buoyant plume $(\sim 100 \mathrm{~m})$ emanating from the terminus of Bagshawe Glacier and extending several kilometers over the inner basin.

Strong buoyant plumes can drive circulation in fjords via the "meltwater pump", but without estimates of volume flux at the 285 glacier grounding line, it is not possible to determine the effect of small amounts of basal melt on circulation in Andvord Bay. While this process is described in-depth for Arctic glaciers, Andvord Bay differs in that ocean temperatures are approximately $-1{ }^{\circ} \mathrm{C}$ at depth, too cold to ablate the glacier terminus, and neutral buoyancy is reached below the surface layer (indicated by subsurface sediment plumes, Domack and Ishman 1993). However, two important consequences of these plumes are a flux of suspended particulate matter contained within "layers" of high beam attenuation coefficient and particle backscatter (Fig. S3 in Pan et al. 2019), and general mid-water cooling found in the inner fjord (Figure 8 in Lundesgaard et al. 2020). Downstream 
mixing mechanisms, such as flow over topographic features or wind induced upwelling, could displace plume water closer to the euphotic zone.

\subsection{Water column trace metals}

Dissolved Fe concentrations in the surface, defined as the upper $\sim 20 \mathrm{~m}$ based on similar mixed layer depths (MLD) for both 295 seasons, changed seasonally with an overall increase in dFe concentration following the summer (Fig. 3). The average surface concentration during late-Spring was $2.47 \pm 0.92 \mathrm{nM}(n=21)$, while in Fall it was $6.67 \pm 1.41 \mathrm{nM}(n=19)$. Water column trace metals are presented in SI Table 1. These concentrations are within the ranges of dFe determined in prior studies (1-31 nM) in the northern WAP region but indicate that large temporal variability exists in surface waters in this region (Hatta et al. 2013; Sanudo-Wilhelmy et al. 2002; Ardelan et al. 2010; Martin et al. 1990). The smaller range of surface concentrations during late-Spring suggests that $\mathrm{dFe}$ was more tightly controlled by removal processes, whereas in the Fall, patchiness among stations arises due to varying proximity to Fe sources and the effects of circulation and mixing. Vertical profiles of dFe showed a steep increase to values greater than $10 \mathrm{nM}$ at the deepest depths sampled during late-Spring, especially at stations located within the inner fjord and basins (Fig. 2, 4). In the subsurface $(50-150 \mathrm{~m}$ ), an enriched dFe source was present with average concentrations $3.68 \pm 1.52 \mathrm{nM}$ in late-Spring and $7.38 \pm 2.49 \mathrm{nM}$ in the Fall. Deep water masses greater than $150 \mathrm{~m}$ deep had the

305 highest average concentrations of $\mathrm{dFe}$ for both seasons and showed remarkable similarity in concentration $(9.23 \pm 4.35 \mathrm{nM}$ in late-Spring, $9.25 \pm 3.48 \mathrm{nM}$ in Fall). The greatest concentrations of dFe were found in the inner fjord and basin stations, with the exception of one station located at the mouth of the fjord near Aguirre Channel (station AC in Fig. 1). Water column concentrations were lower in the Gerlache Strait and fjord mouth. The general shapes of the profiles in late-Spring are characteristic of a stratified water column, with dramatic ferriclines below the surface.

310 Following the summer, higher concentrations of dMn were observed in the surface compared to the late-Spring, while the dissolved Mn:Fe ratio decreased overall and was more variable than in late-Spring, when concentrations of dMn remained below 4.5nM, even at depth. Concentrations of dMn more than doubled at all stations. Labile particulate $\mathrm{Mn}(\mathrm{LpMn}=\mathrm{TDMn}$ $-\mathrm{dMn}$ ) showed strong co-variation with LpFe and beam attenuation coefficient $\mathrm{c}(660)$. The comparatively high surface dissolved Mn:Fe ratios in late-Spring were presumably due to intense biological drawdown of Fe during the vernal bloom, 315 evidenced from low concentrations of $\mathrm{dFe}$ where phytoplankton biomass was highest, as indicated by Chlorophyll-a concentrations (Fig. 5a). In the late-Spring, a relationship between meltwater fraction and dFe exists, where lower $\mathrm{dFe}$ concentrations are found where MWf is greatest (Fig. 5c). There was no significant trend between dFe, biomass and MWf variables in the Fall (Fig. 5b,d). The correlation between dMn and dFe was stronger in the Fall, compared to the late-Spring (Fig. 5e,f).

320 Labile particulate iron $(\mathrm{LpFe}=\mathrm{TDFe}-\mathrm{dFe})$ concentrations were elevated in the inner basins and in the Fall, strongly correlated with suspended particle concentrations, indicated by optical beam attenuation coefficient c(660) $\mathrm{m}^{-1}$ (Fig. 5n, 6). Average LpFe concentrations in the surface were comparable to surface waters in Ryder Bay (southern Antarctic Peninsula), where TDFe 
varied temporally from 57 to $237 \mathrm{nM}$ (Annett et al., 2015). This comparison between LpFe and TDFe is valid since TDFe is much greater than $\mathrm{dFe}$ in these two coastal locations. LpFe maxima were associated with high turbidity in the inner basins, reaching as high as $900 \mathrm{nM}$ at 300m depth in the Fall (Fig. 6). Dissolved Fe and LpFe were highly correlated $\left(\mathrm{r}^{2}=0.48\right.$ lateSpring $n=19 ; 0.77$ Fall $n=28$ ), implying active exchange between these pools (Fig. 5g,h). On average, dFe made up 3.1\% (late-Spring) and 4.6\% (Fall) of the total dissolvable pool. LpMn concentrations displayed similar seasonality to LpFe and association with particles, but were more strongly correlated in the Fall (Fig. 51). Dissolved Mn and LpMn were highly correlated $\left(\mathrm{r}^{2}=0.70\right.$ late-Spring $n=19 ; 0.79$ Fall $n=28$; Fig. 5i,j). On average, dMn comprised 51.8\% (late-Spring) and 56.5\% (Fall) of the total dissolvable pool.

\subsection{Glacial ice and plume trace metals}

Glacial ice and plume samples were analyzed for Fe, Mn, Al, and Ti concentrations, which are presented in Table 1. Three glacial ice samples were analyzed for $\mathrm{dFe}(71.52 \pm 121.31 \mathrm{nM})$ and $\mathrm{dMn}(49.43 \pm 82.64 \mathrm{nM})$. Visual inspection of Glacial Ice 3 and 4 showed these pieces contained low particle loads, while Glacial Ice 1 and 2 had a comparatively high content of dark colored coarse-grained particles. These latter two icebergs had dark layers of sediment embedded in the ice, and so together with the other pieces, represent the variability of trace metal concentrations in icebergs found in Andvord Bay. Labile particulate trace metal concentrations were two orders of magnitude higher than the dissolved fraction based on two ice samples $(40.71 \pm 85.58 \mu \mathrm{M} \mathrm{LpFe}, 3.64 \pm 5.06 \mu \mathrm{M} \mathrm{LpMn})$. We did not have corresponding labile particulate trace metals for Glacial Ice 3 and 4 , thus the average labile particulate concentration was skewed toward a high value. Total particulate trace metals showed similar variability in concentration as the dissolved fraction $(94.87 \pm 181.08 \mu \mathrm{M}$ TpFe, $2.66 \pm 5.06 \mu \mathrm{M}$ TpMn). For Glacial Ice 3 and 4, the concentration of dMn was greater than TpMn. The ratios of labile and total particulate Mn:Fe were $0.061 \pm 0.002$ mol:mol and 0.028 $\pm 0.004 \mathrm{~mol}: \mathrm{mol}$, respectively.

Dissolved $\mathrm{Al}$ and Ti were not analyzed for these ice samples, but total dissolvable and total particulate samples were analyzed for Glacial Ice 1 and 2, and 1-4, respectively. We defined the refractory particulate trace metal concentration as the difference

345 between the total particulate and total dissolvable fractions ( RpTM = TpTM - TDTM). Total dissolvable Al and Ti average concentrations were skewed due to the heavy particle load present within the samples (603.2 $\pm 715.68 \mu \mathrm{M}$ TDAl, 20.75 \pm 27.06 $\mu \mathrm{M}$ TDTi). Total particulate $\mathrm{Al}$ and Ti had similar variability to the total dissolvable fraction and included all four glacial ice samples in the average $(428.11 \pm 790.46 \mu \mathrm{M} \mathrm{TpAl}, 13.41 \pm 25.68 \mu \mathrm{M} \mathrm{TpTi})$, therefore the average total particulate concentrations were lower than the average determined for total dissolvable $\mathrm{Al}$ and $\mathrm{Ti}$. We found the labile particulate 350 concentration to be a valid comparison to total dissolvable since $\mathrm{dFe}$ concentration was an average $1.8 \pm 1.5 \%$ of $\mathrm{TpFe}$ concentration. Therefore, the particulate fraction dominated trace metal speciation of total Fe, Mn, Al, and Ti in glacial ice. Four seawater samples were collected from 100-110 m depth, corresponding to the core of the subsurface turbidity plume within IBA. Average concentrations of dissolved metals were $8.75 \pm 2.25 \mathrm{nM}$ dFe and $5.52 \pm 0.62 \mathrm{nM} \mathrm{dMn}$. LpFe $(350.70 \pm 147.92 \mathrm{nM})$ and $\mathrm{LpMn}(8.23 \pm 2.68 \mathrm{nM})$ were statistically indistinguishable from the total particulate fractions 
(415.84 $\pm 93.01 \mathrm{nM} \mathrm{TpFe}, 9.52 \pm 2.05 \mathrm{nM} \mathrm{TpMn})$. The average ratio of labile particulate Mn:Fe was $0.024 \pm 0.003 \mathrm{~mol}: \mathrm{mol}$. Particles collected from the plume had high concentrations of $\mathrm{Al}$ and $\mathrm{Ti}$, but with distinctly different lability than $\mathrm{Mn}$ and Fe. TDAl was $894.09 \pm 68.48 \mathrm{nM}$ while TpAl was $1734.32 \pm 368.79 \mathrm{nM}$. Similarly, TDTi was $14.06 \pm 0.45 \mathrm{nM}$ and TpTi was $45.08 \pm 10.69 \mathrm{nM}$. The total dissolvable Al:Ti ratio was $64 \pm 6 \mathrm{~mol}: \mathrm{mol}$ and the total particulate Al:Ti ratio was $39 \pm 1 \mathrm{~mol}: \mathrm{mol}$.

\subsection{Glacial sediments}

360 Solid phase Fe speciation of one sediment core from the outer basin station (OB, 64 46' 46' ' $\mathrm{S}, 62^{\circ} 43^{\prime} 57^{\prime}$ ' W, 500m, collected in January 2016), showed an enrichment of authigenic Fe oxides at the surface. Chemical treatments of the sediments with $\mathrm{HCl}$ dissolves poorly crystalline $\mathrm{Fe}$ oxy(hydr)oxides (ferrihydrite and lepidocrocite), which are found to be $10 \%$ of the total particulate $\mathrm{Fe}$ of the surface sediments in this location, compared to an average of $2 \%$ below $1.5 \mathrm{~cm}$ (SI Fig. 3). In the surficial sediments, a larger portion of the Fe is associated with poorly labile sheet silicates (e.g. structural Fe(III) in clays,

$36536 \%$ ), and a comparable fraction is refractory and is not liberated by any of the solution treatments (31\%). Other fractions of particulate $\mathrm{Fe}$ are associated with more crystalline and less labile Fe oxides (goethite, hematite) and the minerals magnetite and pyrite. Porewater analyses were performed on two OB cores using colorimetric methods, revealing high concentrations of $\mathrm{dFe}$ and $\mathrm{dMn}$. Below the well-oxygenated layer (upper $\sim 0.5 \mathrm{~cm}$ ), but within the upper $10 \mathrm{~cm}, \mathrm{dFe}$ reaches its peak concentration of $80 \mu \mathrm{M}$, while maximum dMn is $6 \mu \mathrm{M}$. Down-core from the peak, concentrations tend to decrease for both trace metals, but

370 there is considerable variability between 15 and $25 \mathrm{~cm}$, including several deeper local maxima. The average porewater concentration of dFe in the top $2.5 \mathrm{~cm}$ is $26 \mu \mathrm{M}$ (SI Fig. 2). There is considerable difference in the porewater concentrations of the two OB cores indicating post-depositional reworking of the sediments resulting in large variability on small scales. Points excluded from the oxygen profiles were below the detection limit, while several samples were missing from the porewater profiles, represented as gaps in the vertical trace of dFe and dMn.

\section{$375 \quad 3.5$ Fe-binding organic ligands}

To gain insight into the speciation of dFe with the fjord, we analyzed seawater samples for Fe-binding ligands and to identify comparative strengths of organic Fe complexes (See Methods). Analysis of the ligands within Andvord Bay shows a downfjord gradient in both quantity and quality (all ligand data are presented in Table 2). In the late-Spring, strong ligands $\left(\log K_{F e L, F e^{\prime}}^{c o n d} \geq 12.0\right)$ were detected in the surface at stations located within the fjord at concentration levels ranging from

$3804.06 \pm 1.74 \mathrm{nM}$ at Inner Basin A (IBA) to $7.27 \pm 1.97 \mathrm{nM}$ at Sill $3(\mathrm{~S} 3)$, while only weak ligands $\left(\log K_{F e L, F e^{\prime}}^{\text {cond }}<12.0\right)$ were detected in the Gerlache Strait (GS; $5.72 \pm 2.21 \mathrm{nM}$ ). An excess of strong ligands, relative to $\mathrm{dFe}$, was detected in the inner basins. A gradient in concentration of undersaturated ligands (eL in Table 2) is observed towards the GS, with increasing eL. Within the fjord, weak ligands were detected at Inner Basin B (IBB), closest to Moser Glacier. In the Fall, total ligand concentrations $\left(\mathrm{L}_{\mathrm{t}}\right)$ were elevated everywhere within the fjord, but the surface ligands were somewhat weaker compared to the late-Spring. The greatest concentrations of ligands were found closest to the glaciers (range $11.18-15.42 \mathrm{nM}$ ) and in the GS 
$(12.00 \pm 2.94 \mathrm{nM})$. For both seasons, weak ligands were detected in the subsurface, but a greater concentration in the Fall suggested that these ligands have a local source within the fjord. Compared to other stations in the Fall, we found the plume to contain a small excess of weak ligands (IBA, $110 \mathrm{~m})$. Interestingly, the highest concentration of strong ligands $(17.44 \pm 1.12$ $\mathrm{nM}$ ) detected anywhere was in deep water of Station IBA, at $280 \mathrm{~m}$. This is the deepest depth sampled for Fe-binding ligands

390 and the IBA bottom depth was $382 \mathrm{~m}$. We found a down-fjord gradient in ligand strength at the surface, decreasing with distance from the inner basins $\left(\log K_{F e L, F e^{\prime}}^{c o n d}=11.95\right.$ at IBA, 11.03 at GS $)$.

We determined the free (uncomplexed) Fe concentration (Fe' in Table 2) within samples analyzed for Fe-binding ligands. In the surface, a greater concentration of Fe' was found in the Fall $(8.74 \pm 6.43 \mathrm{pM}, n=7)$ compared to the late-Spring $(2.44 \pm 2.18$ $\mathrm{pM}, n=7)$. Water below the surface showed similar concentrations for each season (5.8 $\pm 0.21 \mathrm{pM}$ late-Spring, $4.61 \pm 2.22 \mathrm{pM}$

395 Fall). The greatest concentrations of Fe' were observed mid-fjord at the surface (18.7 pM Fe' at MBA, 15.67 pM Fe' at S3) in the Fall.

\subsection{Dye experiments}

To study the transport pathways for $\mathrm{dFe}$, we use numerical passive dyes in the Hahn-Woernle et al. (2020) regional model of Andvord Bay (see Fig. 1 in Hahn-Woernle et al. 2020) to track three potential sources of dFe: surface glacial meltwater (0-50

$400 \mathrm{~m}$ ) from Bagshawe and Moser Glacier termini, neutrally-buoyant subsurface plume (100 m), and deep water located in IBA (300 m; as in Methods). Due to numerous inputs and complex biogeochemical processes which result in observed $\mathrm{dFe}$ distributions in time and space, we simplify the problem by assuming no removal over the duration of simulated dye experiments. We use this approach to illustrate the multiple transport pathways for dFe supply to the fjord and surrounding ocean from December through March (St-Laurent et al., 2017). The results are presented first for the surface meltwater

405 experiment, followed by two fixed-volume experiments, referred to as subsurface and deep dye experiments.

Most of the surface glacial meltwater dye remains in the upper $100 \mathrm{~m}$ throughout the model run, and due to its proximity to the surface, it is quickly dispersed over a large region by relatively rapid surface currents. It takes about 10-15 days for the surface meltwater to exit the fjord mouth, where most ends up in the central and northern Gerlache Strait after 120 days (SI Fig. 4a).

410 The subsurface dye $(100 \mathrm{~m})$ is spread more rapidly than the deep dye $(300 \mathrm{~m})$. After 8 days, the subsurface dye reaches the fjord mouth, which is 4 days before the deep dye, implying it has a shorter residence time within the fjord compared to the deep dye. We loosely define residence time as the model timestamp at which a fixed fraction of dye remains within the fjord domain. After 22 days, $25 \%$ of the subsurface dye has left the fjord, while it takes the deep dye almost twice as long (43 days). At the end of the 120 days long model run, less than $18 \%$ of the subsurface dye and over $30 \%$ of the deep dye remain in the

415 fjord domain (SI Fig. 5a). Looking at the whole model domain in Fig. 1, which includes Andvord Bay and Gerlache Strait, only $59 \%$ of the subsurface dye and $75 \%$ of the deep dye are still present. The missing $41 \%(25 \%)$ has mainly left the model domain through the Gerlache Strait to the north, where these waters mix with Bransfield Strait water and subsequently with the southern Antarctic Circumpolar Front waters. 
We analyzed the vertical distribution of the subsurface and deep dyes along the fjord mouth and horizontally over different

depth layers. Within the first day, the subsurface dye spreads over the depth range of 20 to $125 \mathrm{~m}$ and the deep dye over 125 to $500 \mathrm{~m}$ ( $>1 \%$ of dye per depth layer). The subsurface dye leaves the fjord mainly within the upper $200 \mathrm{~m}$. After 8 days, as the subsurface dye reaches the fjord mouth (SI Fig. 4b), the maximum concentration is still found close to its release depth at $100-125 \mathrm{~m}$. Over the next few days, surface layer concentrations $(<20 \mathrm{~m})$ increase, but the highest concentration is soon found below 125m (after 2 weeks) (SI Fig. 5a).

425 The deep dye remains mainly below $200 \mathrm{~m}$ as it passes the fjord mouth (maximum water depth at the fjord mouth is $360 \mathrm{~m}$ ). After 12 days, as the deep dye reaches the fjord mouth, the maximum concentration is found below $300 \mathrm{~m}$ depth. In contrast to the subsurface dye, the deep dye remains longer in the proximity of the fjord mouth and on several occasions, re-enters the fjord leading to a longer residence time within the fjord (SI Fig. 4c). The majority of the deep dye leaves the fjord at depths below $100 \mathrm{~m}$ and along the southwestern coastline. Both dyes, subsurface and deep, have low concentrations in the upper 100

$430 \mathrm{~m}$ of the northeastern flank of the fjord mouth. This is due to the inflow of external water from the GS along the northeastern coastline. Throughout the run, the deep dye is confined to the inner basins of the fjord. In all cases, the dyes remain at higher concentrations and for longer periods in the subsurface fjord waters than in the surface layer, which shows faster transport out of the fjord.

\section{Discussion}

\section{4.1 Iron sources in a heavily glaciated fjord}

Due to the proximity to glaciers and influence of ice within Andvord, we hypothesized meltwaters to be an important source of Fe. We focus on quantifying dissolved, total dissolvable and particulate $\mathrm{Fe}$ and $\mathrm{Mn}$, as well as total dissolvable and particulate $\mathrm{Al}$ and $\mathrm{Ti}$. Ratios of these elements are treated as proxies for contributions of various endmembers. Candidate endmembers include reducing sediments, weathered crustal material, and biogenic particles (Taylor and McLennan 1995;

440 Twining et al. 2004). Where possible, we estimate fluxes of dFe. We begin by examining the relationship between glacial meltwater and $\mathrm{dFe}$.

\subsection{Role of surface glacial meltwater}

There exists a weakly negative correlation between derived MWf and dFe at the start of the melt season (late-Spring: $\mathrm{r}^{2}=0.29$, $\mathrm{n}=30$; early-Fall: $\mathrm{r}^{2}=0.05, \mathrm{n}=13$; Fig. $5 \mathrm{c}, \mathrm{d}$ ). One possible explanation is that increased meltwater at the surface leads to greater stratification and limits upwelling of Fe-rich deep water in conjunction with removal processes, such as biological drawdown and scavenging onto sinking particles. Indeed, higher rates of primary production are associated with greater fractions of meltwater in Andvord Bay (Pan et al., 2020). Since glacial meltwater is restricted to the surface, it constitutes a significant input of $\mathrm{Fe}$ to the surface throughout the growth season. While we observe high concentrations of dissolved and particulate trace metals within glacial ice, we note that the icebergs within Andvord were predominantly "clean" ice, with little 

on Fe:Al ratios in particles and average values for continental crust (Taylor and McLennan 1995), we estimate $87 \pm 22 \%(n=$ 4) of the particulate Fe contained within Andvord icebergs is terrigenous in origin. This is consistent with mechanical weathering of continental crust followed by inclusion of the particles into the ice (freeze-in, Raiswell et al. 2018). Low Fe:Ti and $\mathrm{Al}$ :Ti ratios also reflect a continental crust source, but it is worth noting that Glacial Ice 2 had significantly more Mn and

$455 \mathrm{Al}$, relative to continental $\mathrm{Fe}$ and Ti. Further, $\mathrm{Mn}$ and $\mathrm{Al}$ speciation suggests there are high concentrations of Mn- and Aloxides, which may be formed when crustal material is altered (Raiswell et al. 2018). It is also possible that fjord sediments were the source of particulate matter within Glacial Ice 2, which would correspondingly have more Mn content (higher Mn:Fe) than what is found in basal ice interacting with the subglacial environment (Hawkings et al., 2020). Continental crust material delivered to the ocean would contain a relatively low $\mathrm{Mn}$ content compared to $\mathrm{Fe}$ ( $\mathrm{Fe}$ is $4 \%$ in crustal material, while $\mathrm{Mn}$ is $460 \quad 0.08 \%$, Rudnick and Gao 2013).

Visual inspection suggests that the majority of the ice within Andvord has relatively low concentrations of particles, whereas basal ice, with dark layers of sediments (Glacial Ice 1 in Table 1), will likely skew the average towards high values (Hopwood et al. 2019). A compilation of TDFe in icebergs in Antarctica estimated an average concentration of $24 \mu \mathrm{M}$ (Hopwood et al. 2019). Our two measurements of $\mathrm{LpFe}$ in glacial ice are different (average for this study is $61 \pm 70 \mu \mathrm{M} \mathrm{LpFe}, n=2$ ) but are

465 within the range of concentrations determined in the previous study. Even so, we use the average concentration (Table 1) as indicative of the glacial conditions encountered in Andvord to compute the following meltwater fluxes. Using a range of estimated surface glacial meltwater inputs to Andvord $\left(2.4 \times 10^{4} \mathrm{~m}^{3} \mathrm{~d}^{-1}\right.$ for this study based on oxygen stable-isotope mass balance; $1.8 \times 10^{4}$ to $1.2 \times 10^{5} \mathrm{~m}^{3} \mathrm{~d}^{-1}$ Lundesgaard et al. $2020 ; 1.1 \times 10^{6} \mathrm{~m}^{3} \mathrm{~d}^{-1}$ Hahn-Woernle et al. 2020 including other freshwater sources that are not precipitation) and assuming the input of meltwater is distributed evenly over the fjord surface layer, we calculate fluxes on the order of 15.1 to $704 \mathrm{nmol} \mathrm{m}^{-2} \mathrm{~d}^{-1}$ for $\mathrm{dFe}$ and 10.4 to $487 \mathrm{nmol} \mathrm{m}^{-2} \mathrm{~d}^{-1}$ for dMn. Based on modeling work in this paper, it will become evident that meltwater released to Andvord does not stay within the fjord. Additionally, significant metal loss might result from scavenging processes, transferring Fe to depth on sinking particle surfaces, rendering it inaccessible for phytoplankton uptake. Still, the availability of excess macronutrients within Andvord Bay means that substantial increases in the supply of trace metals from glacial meltwater would stimulate growth in the euphotic zone, if light is not limiting.

\subsection{The nature of Fe in subglacial plumes}

The inner basins consistently show higher beam attenuation and particle backscattering coefficients than mid-fjord and shelf stations (see Figure 3 in Supplementary Information in Pan et al. 2019). These signals are attributed to ultra-fine suspended sediments $(<0.7-0.8 \mu \mathrm{m})$. The high particle backscattering coefficient in the surface at all stations in late-Spring is due to the

480 high concentrations of biogenic particles associated with the vernal bloom. Inner basins also show maximal beam attenuation coefficients at 70-150 m, as well as approaching the benthic boundary layer (Fig. 6). Sediments that originate near the glacier terminus are carried upward in buoyant turbulent plumes, and spread laterally. This is consistent with the presence of glacial 
meltwater plumes, or "cold tongues", which originate at the glacier grounding line (described in Domack and Williams 2011), entrain deep water masses, and suspend sediments (Straneo and Cenedese, 2015). Since ocean temperatures remained below

$0^{\circ} \mathrm{C}$ in Andvord (see Fig. 2), there is little to suggest basal melting of the ice, as is observed further south along the WAP. It appears reasonable on the basis of the evidence given above, that the subsurface plume signature is subglacial in origin.

Total digestion and subsequent analyses of marine particles collected within the plume reveal high concentrations of weathered crustal sediments $(82-86 \% \mathrm{TpFe}, 61-64 \% \mathrm{TpMn})$, and also ingrowth of authigenic particles most likely consisting of precipitated Fe- and Mn-oxide phases (16-18\% TpFe, 36-39\% TpMn). These results suggest the origin of plume particles are

490 a chemically-altered crustal source. We probed the chemical lability and found LpFe and TpFe concentrations within the plume are nearly identical within measurement error, including filter splitting and sample distribution uncertainties. Labile particulate $\mathrm{Fe}$ is $82-100 \%$ of TpFe (Table 1). The Fe:Al and Fe:Ti in plume particles $(0.24 \pm 0.01 \mathrm{~mol}: \mathrm{mol}$ and $9.25 \pm 0.24 \mathrm{~mol}: \mathrm{mol}$, respectively) were elevated above the average crustal ratios ( $0.2 \mathrm{~mol}: \mathrm{mol} \mathrm{Fe:Al,} 7 \mathrm{~mol}: \mathrm{mol} \mathrm{Fe}: \mathrm{Ti})$, which implies these samples are enriched in Fe relative to both crustal $\mathrm{Al}$ and Ti. In agreement with these results, particulate Al:Ti (39 \pm 1 mol:mol) was 495 elevated above crustal ratios ( $35 \mathrm{~mol}: \mathrm{mol})$, indicating a large oxide fraction is associated with this particulate matter. This substantiates our claim that most of the Fe found in the plume is weakly adsorbed to particles and recently precipitated, since dilute $\mathrm{HCl}$ leaches liberate the most labile forms of $\mathrm{Fe}$, most likely as oxy(hydr)oxides (e.g. ferrihydrite) in addition to some Fe from clays. This could include oxides directly precipitated from the subglacial source, as well as a potential fraction of oxides derived from fjord sediments and porewaters entrained at the grounding line.

500 Cold-based glaciers are locations where the subglacial environment flows directly into the fjord with minimal mixing with seawater. We find elevated concentrations of dMn emanating from the inner fjord, indicative of the reducing conditions beneath Moser and Bagshawe glaciers, consistent with other studies of subglacial environments (Henkel et al. 2018; Zhang et al. 2015). We report relatively low concentrations of $\mathrm{dFe}$ within the plume $(8.75 \pm 2.25 \mathrm{nM})<1 \mathrm{~km}$ away from the glacier terminus. This value is much lower than the range used to parameterize subglacial inputs from ice shelves to the SO $(3-30 \mu \mathrm{M}$ in Death et

505 al. 2014). This perhaps indicates a major difference between glaciers containing large volumes of subglacial meltwater that accumulate the products of more extensive reductive chemical weathering, and smaller glaciers situated on steep topography and which feed into fjords, such as those along the WAP. The long residence time and enhanced chemical weathering beneath large glaciers in west Antarctica (PIG, Thwaites Glacier) could result in large accumulations of dissolved trace metals in subglacial outflow. However, it should be noted that subglacial discharge from ice shelves is separated from the continental shelf due to the broad floating horizontal tongues of ice shelves, which make up about $45 \%$ of the Antarctic coastline and can extend 10s - 100s km from the shelf (Schodlok, Menemenlis and Rignot, 2016). Our results suggest that assuming such high export efficiency to the coastal ocean (i.e., using endmember concentrations from glacial runoff and groundwaters as in Death et al. 2014) potentially overestimates $\mathrm{dFe}$ supply from the subglacial environment because dFe rapidly precipitates after mixing with seawater. 
Analyses of Andvord Bay sediments reveal they are compositionally distinct from temperate fjords consisting of poorly sorted fine silt and clay, many dropstones, suspension deposits and ice-rafted debris (Eidam et al., 2019). Sediment accumulation rates are spatially variable, but a weak along-fjord gradient is present. These deposits suggest sluggish circulation, allowing for the deposition of sediments close to their source, likely through flocculation processes (Cowan and Powell, 1990).

520 Profiles of beam attenuation coefficient show highest concentration of particles in the inner basins compared to other station locations (see Figure 4 in Pan et al., 2019). There is little evidence for mechanical resuspension through gravity flows (i.e., turbidites) along the steep basin walls, yet such processes could be responsible for the near-bottom elevation in water column particles (Eidam et al., 2019). The presence of elevated particles in the inner basins is accompanied by the greatest concentrations of dissolved and labile particulate Fe and Mn (Fig. 6), demonstrating the potential of resuspended fjord

525 sediments as a source of dissolved trace metals.

Based on the core top porewater profiles, we estimate the sedimentary efflux to be $43.7 \mu \mathrm{mol} \mathrm{m}^{-2} \mathrm{~d}^{-1}$ for $\mathrm{dFe}$ and $7.2 \mu \mathrm{mol} \mathrm{m}$ ${ }^{2} \mathrm{~d}^{-1}$ for $\mathrm{dMn}$, due to diffusion alone (SI Fig. 2). This magnitude of flux was also observed in the shelf sediments in the vicinity of South Georgia Island in the SO (Schlosser et al., 2018). Abundant epibenthic fauna were observed within Andvord Bay, which mix the sediments through bioturbation while consuming labile organic matter. The result is deviation from results

530 based on diffusion alone. Taylor et al. (2020) used ${ }^{234} \mathrm{Th}$ as a proxy to investigate the effect of bioturbation on short timescales and found Andvord Bay sediments possess a high mixing coefficient down to $5 \mathrm{~cm}\left(D_{b}=36 \mathrm{~cm}^{2} / \mathrm{yr}\right)$ consistent with greater deposition and subsequent utilization of organic carbon in the sediments. We believe this accurately reflects the conditions in this fjord: bioturbation by dense aggregations of epibenthic fauna within the basins.

These results are not surprising when compared to a global compilation of in situ measurements of sedimentary efflux of dFe,

535 which is on average $\sim 12 \mu \mathrm{mol} \mathrm{m}^{-2} \mathrm{~d}^{-1}$ for water masses located on continental margins and with $\mathrm{O}_{2}$ concentrations greater than $63 \mu \mathrm{mol} \mathrm{L}{ }^{-1}$ (Dale et al., 2015). The bottom water oxygen concentration in Andvord Bay always exceeded $230 \mu \mathrm{mol} \mathrm{L} \mathrm{L}^{-1}$. The bottom water $\mathrm{O}_{2}$ concentration for $\mathrm{OB}$ at the time sediments were cored, was $270 \mu \mathrm{mol} \mathrm{L} \mathrm{L}^{-1}$. In the Ross Sea, Marsay et al., (2014) estimated spatially variable efflux spanning 0.028-8.2 $\mu \mathrm{mol} \mathrm{m}{ }^{-2} \mathrm{~d}^{-1}$ based on water column dFe profiles (Marsay et al., 2014). Abundant epibenthic fauna found within Andvord (Ziegler et al. 2017, 2020) would introduce oxygen to the upper few 540 centimeters of the sediments through bioturbation and reduce the efflux of reduced metals (Severmann et al., 2010). Taylor et al., (2020) found the upper 5 centimeters of Andvord Bay sediments possessed a high mixing coefficient relative to open shelf stations and Palmer Deep. Additionally, high inventories of ${ }^{210} \mathrm{~Pb}$ relative to open shelf and Palmer Deep stations indicate a high mixing coefficient for sediments between 7 and $22 \mathrm{~cm}$ depth on timescales of 100 years (Taylor, DeMaster, and Burdige 2020). The effect of this process is mixing of oxide- and organic carbon-rich surficial sediments further down in the core on

545 short- to long-timescales. These flux estimates, together with solid phase speciation results, highlight the importance of rapid oxidation and precipitation occurring, which effectively retain Fe oxy-hydroxides within the sediments (Burdige and Komada, 2020). Fe oxides are enriched within the penetration depth of oxygen $(\sim 0.5 \mathrm{~cm}$, SI Fig. 2 inset $)$ and once bioturbated 
downward, could be a source of soluble Fe following microbial cycling. Multiple local maxima of porewater dFe were observed deeper in the cores. While dissimilatory iron reduction (henceforth, DIR) would be a source for Fe, oxidation of Fe

with bottom water $\mathrm{O}_{2}$ and $\mathrm{Mn}(\mathrm{IV})$ are important sinks and exert a control on the dFe concentration of deep water masses. The deep inner basin water column samples had high dFe concentrations concomitant with high LpFe concentrations (Fig. 2, 6), suggesting substantial loss of porewater $\mathrm{dFe}$ to the water column and rapid formation of authigenic Fe mineral particles. Therefore, the fluxes calculated are maxima because they do not account for oxidative losses at the sediment-water interface (e.g., Burdige and Komada 2020).

555 Due to weak midwater circulation, low tidal energy, and stratification of the surface, a disconnect between deep water masses enriched in $\mathrm{dFe}$ and the surface of Andvord Bay persists during prolonged quiescent periods. For these reasons, we believe sedimentary Fe is restricted to deep water masses and therefore plays a minor role in $\mathrm{dFe}$ concentrations within the upper water column.

The Mn:Fe ratio is a useful signature of the source of dissolved and particulate trace metals in Antarctica and has been applied

560 to the PAL LTER data set (Annett et al., 2017). Applying this same framework to our study, we find that water column dissolved trace metals are heavily influenced by surface glacial ice melt and subglacial meltwater, and to a lesser extent, sediment sources within the fjord, irrespective of season, depth, and meteoric water input (Fig. 7). Due to the shorter residence time of $\mathrm{dFe}$ relative to dMn (i.e., oxidation of $\mathrm{Mn}$ is $10^{7}$ times slower than Fe, Sherrell et al. 2018), we would expect the porewater dissolved $\mathrm{Mn}: \mathrm{Fe}$ ratio to tend towards higher values once exposed to the seawater oxidative front. We therefore cannot rule out porewaters as a source of $\mathrm{dMn}$ to the water column. A similar process occurs within the plume, where the elevated dissolved Mn:Fe (0.65 mol:mol) relative to labile particulate $\mathrm{Mn}: \mathrm{Fe}(0.024 \mathrm{~mol}: \mathrm{mol})$ shows the effect of rapid conversion of $\mathrm{Fe}$ to authigenic mineral particles. Although we do not have comparable measurements for sedimentary labile particulate trace metals, based on labile particulate $\mathrm{Mn}: \mathrm{Fe}$, we find that water column labile particulate $\mathrm{Mn}: \mathrm{Fe}$ ratio is precisely the same ratio as particles found within the subglacial plume, again irrespective of when and where the sample was taken (Fig. 8), suggesting plume particles remain suspended throughout the fjord water column.

\subsection{Organic speciation of dissolved Fe}

It has been hypothesized that excess ligands $\left(\mathrm{eL}=\left[\mathrm{L}_{\mathrm{t}}\right]-[\mathrm{dFe}]\right)$ increase the solubility of particulate Fe phases (Thuróczy et al., 2011; Gledhill and Buck, 2012; Wagener, Schwenke and Barcikowski, 2012; Tagliabue et al., 2019). The persistence of exchangeable pools of $\mathrm{dFe}$ would therefore be controlled primarily by particle assemblage and organic ligand complements, where $\mathrm{pFe}$ dominates total $\mathrm{Fe}$ speciation. We observe a modest increase between late-Spring and Fall in the relative contribution of $\mathrm{dFe}$ to total $\mathrm{Fe}$ ( $4 \%$ to $5 \%$ of TDFe, respectively), implying dFe is controlled by scaling closely to $\mathrm{LpFe}$ (Fig. $5 \mathrm{~g}, \mathrm{~h}$ ) since both pools have large interseason differences. This corresponds to an increase in eL between seasons (average $2.1 \pm 1.3 \mathrm{nM}$ late-Spring $n=9,6.0 \pm 3.2 \mathrm{nM}$ Fall $n=12$ ), and are likely produced during microbial high-affinity uptake or remineralization processes following the termination of a bloom (Gledhill and Buck, 2012; Hogle et al., 2016). The only subsurface sample to contain strong Fe-binding ligands is the deep inner basin adjacent to Bagshawe Glacier (IBA), possibly 
indicating these ligands have a deep sedimentary source. It appears, based on these results, ligands in Andvord Bay have the capacity to complex additional Fe input, as well as prevent significant loss due to scavenging (Thuróczy et al. 2012). The nature of these ligands, taken together with the low concentration of dFe and abundance of LpFe within the plume, we speculate that $\mathrm{Fe}$ minerals are the target for ligand scavenging and perhaps microbial uptake, previously found to occur in deep-sea 585 hydrothermal vent plumes (Li et al., 2014).

While we observe a seasonal increase in the excess ligand concentration, there is no significant change in the ratio of $\mathrm{L}_{\mathrm{t}} \mathrm{dFe}$

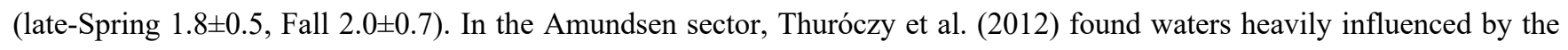
Pine Island Glacier to have Lt:dFe ratios $<2.5$ throughout the water column, with relatively weaker ligands compared with those found in the highly productive surface waters of the Polynya. We too identify weaker Fe-binding ligands associated with 590 the glaciers, and only at MBA and Sill 3 did we observe elevated Lt:dFe (3.13, and 2.99 respectively, in the Fall). In the coastal zone of a remote island in the Bransfield Strait, an excess of strong Fe-binding ligands was observed, hypothesized to indicate Fe-limiting conditions (Buck, Selph and Barbeau, 2010). Temperature and salinity profiles show a strong signature of Bransfield Strait water within Andvord (Lundesgaard et al., 2020). The presence of excess strong Fe-binding ligands at IBA and $\mathrm{S} 3$ during the bloom onset also correspond to elevated $\mathrm{NO}_{3}{ }^{-}: \mathrm{dFe}$ (data not shown) above the threshold for potential Fe-

595 limitation of coastal diatoms in the California Current transition zone ( 10-12 $\mu \mathrm{M} / \mathrm{nM}$ King and Barbeau 2011). The presence of strong Fe-binding ligands suggests an active microbial strategy in this coastal region in order to sequester additional $\mathrm{Fe}$ during the bloom initiation.

The intense seasonality in primary production and the presence of an undersaturated ligand pool could further increase the bioavailability of particles for downstream communities, where particles within the water column are rare. We calculated the 600 capacity for the free Fe-binding ligands to bind $\mathrm{Fe}\left(\alpha_{\mathrm{FeL}}{ }^{\prime}=1+(\mathrm{eL} \cdot \mathrm{K})\right)$. Calculations of $\alpha_{\mathrm{FeL}}$ ' are included for each sample in Table 2 as well as the Fe' inter-seasonal percent change for reoccupied stations ( $\mathrm{R}_{\mathrm{Fe}}$ ). We find the $\alpha_{\mathrm{FeL}}$ ' increased between late-Spring and Fall at IBA, and Sill 4, while a decrease was found at IBB, Sill 3, and Gerlache Strait stations. While all reoccupied stations show an increase in the Fe' concentration $\left(\mathrm{R}_{\mathrm{Fe}}{ }^{\prime}\right)$, the percent change is greatest where $\alpha \mathrm{FeL}$ ' decreased in the Fall. Thus, the seasonal increase in Fe' reflects the increase in dFe concentrations as well as lower complexation coefficient

605 of weaker Fe-ligand complexes, which contribute most to dFe speciation in the Fall and are associated with surface waters adjacent to glaciers.

These first results of organic speciation of $\mathrm{dFe}$ in an Antarctic fjord highlight the importance of seasonal ligand sources in establishing the solubility of new Fe entering the coastal ocean. Seasonality in the ligand pool is not currently represented within SO biogeochemical models (Death et al. 2014; Oliver et al. 2019; St-Laurent et al. 2019; Raiswell et al. 2018; Person 610 et al. 2019). Ligand-mediated complexation has the potential to greatly expand the spatial extent in which solubilization of particulate Fe occurs and could be critical for sustaining productivity over a larger geographical region. Thus, the size, sinking rate, and composition of particles is critical to their lateral transport and reactivity. Our understanding of how cryospheric Fe is transformed after entering the coastal ocean is an important step towards understanding its impact on marine productivity and global biogeochemical cycles with associated feedbacks on climate. For the marine Fe cycle, these geochemical 
615 transformations control the bioavailability of $\mathrm{Fe}$, while vertical advection and mixing supply this critical micronutrient to the surface ocean.

\subsection{Using dye experiments to explore Fe sources and export}

Rapid communication between the surface and subsurface water masses occurs during katabatic wind events. While mixing can be more pronounced in the presence of icebergs, the large magnitude of vertical shear initializes an upwelling cell close to

620 the inner basins of the fjord. Using an idealized model of a fjord, Lundesgaard et al. (2018) found that katabatic winds export the surface layer efficiently, for which several factors are considered important, including the wind velocity, elapsed time of the event, and whether the direction of the wind was along-fjord versus off-axis. Within this idealized model of the fjord, the forcing event leads to outcropping of deeper isohalines (up to 0.3 PSU greater) at the surface along the northern flank of the fjord, corresponding to upwelling (see Figure 11 in Lundesgaard et al. 2019). Wind-induced overturning circulation, along

625 with deepening of the mixed layer by up to $25 \mathrm{~m}$, would increase surface dFe concentrations. These general model results showed wind forcing caused water at depths of 50-150 $\mathrm{m}$ to upwell rapidly (within 24 hours) near the glacier termini. This is an important consequence we explore further in the highly-resolved model representation of the study region by Hahn-Woernle et al., (2020).

The results of the dye experiments allow for the determination of fluxes, either prescribed (in the case of glacial meltwater) or

630 as a result of wind forcing. St. Laurent et al. applied similar methods in the Amundsen Sea with explicit coupling of sea ice ice sheet - ocean interactions (St-Laurent et al., 2017). In a more rigorous biogeochemical model, which included ocean interactions with both sea ice and ice shelves, as well as parameterized Fe reactions, the productive waters in the Amundsen Sea Polynya were supplied by an advected source of dFe from the "meltwater pump" and coastal currents, but this model lacked explicit contributions of subglacial Fe (St-Laurent et al., 2019). These prior modeling results highlight the importance of lateral exchange of the surface with water masses outside the fjord, and so the export out of the fjord mouth is explored.

\subsubsection{Surface meltwater sources and export}

The glacial meltwater flux was estimated in a previous section, assuming the meltwater is distributed evenly over the entire fjord area. We compared the observed and modelled contributions of surface glacial meltwater and subsurface sources to the surface dFe inventory at two key stations, Sill 3 (S3) and Gerlache Strait (GS). We assume that the concentration of dFe is a composite signature of three water masses, with varying relative contributions to the surface inventory. For example, in the late-Spring, at S3, we observed a MWf of 0.0155 and the surface concentration of dFe was $2.49 \mathrm{nM}$ (Fig. 3). Assuming a meltwater end member concentration of $71.52 \mathrm{nM}$ (Table 1), we find that glacial meltwater contributes $1.09 \mathrm{nM}$ (44\% of surface stock) to the surface inventory. In the Fall, the MWf at S3 increased to 0.0226 (Figure 3d), which corresponds to a meltwater contribution of $1.59 \mathrm{nM}$ dFe ( $35 \%$ of surface stock). In the GS, the same analysis reveals that in the late-Spring, the

645 surface had a MWf of 0.0193 , which contributed $1.38 \mathrm{nM} \mathrm{dFe}$ (105\% of surface stock) and in Fall had a MWf of 0.0169 , or $1.21 \mathrm{nM} \mathrm{dFe}$ (24\% of surface stock). It could be the case that the meltwater signature observed in the late-Spring in the GS did 
not originate from Andvord Bay, and thus, might have a different dFe content, but few measurements of dFe in Antarctic glacial ice exist and prevent us from testing this. These results, besides those for GS in the late-Spring, suggest that one or several other sources contribute to the surface inventory of $\mathrm{dFe}$, or the end member concentration is too low. Given that the MWf varies from 1-2.5\% during the time of sampling, it is expected that the input of glacial meltwater throughout the melt season would supply dFe to the surface.

When we examine the time series derived from the model, we find the model consistently underestimates the contribution of meltwater to the surface (SI Fig. 6). MWf does not exceed 0.0013 at either S3 or GS stations, and its seasonal maximum of 0.0046 is found at IBB in early February. Since processes like melting of drifting icebergs and sea ice cannot be captured in 655 the model, the applied meltwater flux is based on a simplified representation of all new freshwater sources except for precipitation in Andvord Bay. These sources include, for example, surface runoff and local melt of glacial ice exposed to the atmosphere. The flux which best recreates observed salinity and temperature profiles in Andvord Bay was achieved by a meltwater input of 0.15 GT over 4 months (Hahn-Woernle et al., 2020).

The overall low modelled meltwater fraction is likely a consequence of multiple factors of which we discuss three. First, the

660 meltwater was tracked only for the field season. The generally low salinity in the upper layer at the beginning of the season and the presence of meltwater dye at the end of the summer season (fjord average of $0.0003 \mathrm{MWf}$ in upper 20m) suggested that meltwater can reside for multiple years in the fjord and cannot be fully captured by our meltwater dye. Second, local melt of glacial ice, e.g. floating icebergs, caused by a summertime surface heat flux, can have a strong impact on the MWf in the surface layer and is likely to be underestimated and not well-represented with the parameterization of the modelled meltwater

665 input. Third, only meltwater from the inner Andvord Bay is tracked and other sources are neglected. Based on other modelled meltwater dyes that track sources just outside Andvord Bay, the impact of the external sources is minor (maximum of 0.0003 MWf in early February) compared to the local sources, but they still contribute to the seasonal increase in MWf.

We extracted vertical profiles of MWf from the model at both stations and found that glacial meltwater originating from Bagshawe and Moser glaciers reaches maximum concentration during the summer bloom (late-January 2016) at Sill 3,

670 relatively constrained to the upper 25m (SI Fig. 7b). In early February, when the bloom was terminated, glacial meltwater concentrations in the fjord decreased due to a weakening meltwater input and dispersal laterally. The weakening input is supposed to reflect the seasonal cycle of ice melting. Ocean circulation dispersed the meltwater into the Gerlache Strait, as shown by a progressive increase in meltwater in the upper water column throughout the melt season (SI Fig. 7a). If the volume flux of meltwater input is indeed correlated to the seasonal air temperature cycle, as it is parameterized in the model, the results

675 in Fig. 3 would reaffirm that meltwater is an important control on the accumulation of phytoplankton biomass within Andvord Bay (Pan et al., 2020).

The effect of the wind on vertical fluxes will vary with wind direction and location within the fjord. The vertical velocity is analyzed for the observation site at Sill 3 and in front of Bagshawe Glacier (IBA). The latter site is an example location for which katabatic winds are expected to lead to intensified upwelling and is also the location of the subsurface and deep dye 

landward-blowing wind generally leads to downwelling, while seaward-blowing katabatic wind leads to upwelling.

Based on observations of dFe from the late-Spring prior to a wind event on December 11 ([dFe] at 20m: $1.967 \mathrm{nM}$ at S3, 2.006 $\mathrm{nM}$ at IBA), and the modelled maximum vertical velocities during the wind event (2.094 x $10^{-5} \mathrm{~m} \mathrm{~s}^{-1}$ at S3, $5.083 \times 10^{-5} \mathrm{~m} \mathrm{~s}^{-1}$ at IBA), we computed the upwelling flux of dFe into the surface (20m) at Sill 3 and IBA to be $3.54 \mu \mathrm{mol} \mathrm{m}^{-2} \mathrm{~d}^{-1}$ and $8.81 \mu \mathrm{mol}$

$685 \mathrm{~m}^{-2} \mathrm{~d}^{-1}$, respectively. These results shed light on the spatial heterogeneity of upwelling conditions within the fjord. Model results for Sill 3 are supported by late-Spring observations of elevated dFe and low meltwater fraction at this station (Fig. 3). We argue that these punctuated periods of upwelling could be a substantial source of dFe to surface waters in Andvord Bay. Further, this supply, together with the flux of glacial meltwater, provides dFe to fuel phytoplankton community growth.

The efficiency with which wind events export the fjord surface water is explored in the glacial meltwater dye experiment. To

690 account for the changing amount of meltwater in the fjord, export across the fjord mouth in Fig. 9c is given as the percentage of the total amount of dye present within the fjord to resolve the effect of katabatic winds on dispersal dynamics of Fe-rich sources. The meltwater dye experiences up to a 28 -fold increased export into the Gerlache Strait during periods of strong along-fjord wind, primarily through the surface. To analyze the correlation between along-fjord wind velocity and the relative meltwater export, we first apply a 24-hr Gaussian filter to the relative export of glacial meltwater (Fig. 9), to exclude tidal signals. Applying the same filter to the wind time series, we find the wind and export data are positively correlated $(\mathrm{r}=0.628)$. The correlation between export and along-fjord winds supports the results by Lundesgaard et al. (2019) who found that katabatic winds control the export of fjord water. This has important implications for the dispersal of Fe-rich waters downstream, which eventually mix with Fe-poor waters located on the continental shelf.

\subsubsection{Subsurface and deep sources and export}

700 Periods of vertical mixing are shown to occur during katabatic wind events (Lundesgaard et al. 2019, 2020). This could be an important mechanism for supplying additional $\mathrm{dFe}$ from the subglacial plume to the surface within the fjord. Prior to the wind event on December 11, the subsurface dye increases gradually in the upper $20 \mathrm{~m}$ (SI Fig. 5b). With the onset of the wind event, the vertical transport of the subsurface dye into the upper $20 \mathrm{~m}$ intensifies and reaches a maximum of $32.7 \times 10^{3} \mathrm{~m}^{3} \mathrm{~d}^{-1}$. In comparison, the deep dye does not enter the upper $20 \mathrm{~m}$ prior to the wind event and its maximum vertical transport is only 4.2

$705 \times 10^{3} \mathrm{~m}^{3} \mathrm{~d}^{-1}$. It follows that katabatic wind events increase upwelling in front of Bagshawe Glacier and have a particularly strong effect on water masses at intermediate depth. Assuming a mean concentration of $8.75 \mathrm{nM} \mathrm{dFe}$ for the subsurface plume (Table 1) and $8.68 \mathrm{nM} \mathrm{dFe}$ for deep ( $\sim 300 \mathrm{~m})$ IBA waters in the late-Spring, these periods of vertical mixing correspond to $\mathrm{dFe}$ fluxes of up to $2.81 \mathrm{nmol} \mathrm{dFe} \mathrm{m} \mathrm{m}^{-2} \mathrm{~d}^{-1}$ and $0.36 \mathrm{nmol} \mathrm{m}^{-2} \mathrm{~d}^{-1}\left(3.17 \mathrm{nmol} \mathrm{m}^{-2} \mathrm{~d}^{-1}\right.$ combined) based on the subsurface dye and deep dye, respectively. Following the katabatic wind event, which lasted approximately 11 days, model results show that $36 \%$

710 of the subsurface dye has shoaled above $75 \mathrm{~m}$, with $10 \%$ of dye found within the surface layer $(<20 \mathrm{~m}$, SI Fig. 5b). Of the deep water dye, less than $1 \%$ is found within the surface layer. The behavior of the deep water masses contrasts with that of the subsurface water, which corroborates the geochemical data suggesting an insignificant contribution of deep water masses 
to the surface hydrography and thus, to surface $\mathrm{dFe}$ inventory. The vertical fluxes estimated in this section are interpreted as a lower-bound for the contribution of the subsurface plume, since the subglacial plume is a fixed volume, when in reality, subglacial meltwater might be supplied continually throughout the melt season. Compared to the flux of glacial meltwater input, and the flux due to subsurface and deep water mixing, the upwelling flux generated by wind events is the largest by an order of magnitude.

The quicker export of the subsurface dye, and therefore the low surface concentration, is mainly due to its proximity to the ocean surface (SI Fig. 4b). The upper ocean is more subject to changes in the upper ocean dynamics and wind stress. In contrast, the deep dye is exported more slowly and is more continuously released into the Gerlache Strait (SI Fig. 4c). These modeling results provide evidence for the flushing of fjord water to the Gerlache Strait which coincides with periods of intensified winds. Thus, katabatic winds are important both for replenishing the surface Fe concentrations from the subglacial plume as well as exporting Fe-rich surface waters. It is reasonable to assume that in the absence of a strengthened buoyancydriven overturning circulation, sources from fjord sediments are limited in supplying the surface with dFe in Andvord Bay.

\section{Conclusion: Andvord Bay as a source of Fe}

We have shown that in the absence of buoyancy-driven upwelling, the interaction of the ice sheet, atmosphere, and surface ocean, is important for resupplying the surface waters with Fe throughout the summer season, leading to enhanced productivity and sedimentation of carbon. Katabatic wind events result in pulsed export of the surface layer, while upwelling and vertical mixing entrains subglacial plume water in the inner fjord. Observed surface concentrations of dFe in Fall lend support to the modelled dynamics (see Fig. 3). We summarize the findings of this study in a conceptual diagram showing important seasonal sources of Fe during the growth and melt season (Fig. 10). We highlight important processes in the diagram using circled number notation. We found ocean temperatures are cold (1) and do not melt the fronts of glaciers, but warm summer atmospheric temperatures contribute to the surface melting of glacial ice (2). Variability in dissolved and particulate concentrations in glacial ice produces large uncertainties in the calculated flux. The speciation of Fe within glacial ice is mostly composed of refractory Fe-bearing particles (3). Only a fraction may be stabilized by excess organic ligands. Another source is fjord sediments (4), though there is considerable uncertainty shown in the magnitude of this flux because evidence indicates that a significant fraction of porewater Fe rapidly precipitates at the oxidative front forming a rich surface layer of $\mathrm{Fe}$ oxyhydroxides (5). Intense bioturbation of fjord sediments mixes the surface sediments downwards fueling dissimilatory reduction processes. $\mathrm{dFe}$ that escapes this sink enriches deep waters within the fjord. Small amounts of subglacial meltwater discharge enter the ocean and form turbid subsurface plumes (6). Within the plume, speciation is dominated by high concentrations of labile authigenic Fe-bearing particles that can be solubilized by Fe-binding organic ligands (7). Seawardblowing katabatic winds 8 occur episodically and cause upwelling and vertical mixing supplying additional Fe to the surface phytoplankton community. These intense energetic periods facilitate the dispersion and export of surface Fe and meltwater away from the fjord where it is advected downstream (9. 
745 Given the west Antarctic Peninsula hosts the greatest number of glaciomarine fjords on the continent, and multiple katabatic wind events occur throughout the year, single wind events can play a crucial role for the export of Fe. The modelled export of meltwater integrated over the week after the wind event on December 11 is $38 \times 10^{7} \mathrm{~m}^{3}$, which is about $43 \%$ of the meltwater input during the same time. For comparison, during the following week, with relatively calm wind conditions, only $20 \%$ of the meltwater input is exported. We estimate the Fe export to be $272 \mathrm{~mol} \mathrm{dFe} \mathrm{week}^{-1}$ for this event. However, the warming

750 climate may lessen the likelihood for pulsed export of meltwater-derived Fe by intensifying coastal currents due to declines in sea ice (Moffat et al., 2008), and reduced surface cooling, decreasing the velocity and frequency of katabatic winds over the west Antarctic Ice Sheet (Bintanja et al., 2014).

The large variability in inferred dFe content of glacial meltwaters along the WAP (Annett et al., 2017) means that supply likely depends on fjord-specific processes and future changes in ice volume. Advected sources of dFe remain the largest contribution $755(\sim 50 \%)$ to the inventory on the productive continental shelves (De Jong et al., 2015). Therefore, we believe that a latitudinal assessment of WAP fjords could begin to address variable responses to ocean and atmospheric forcing in these productive ecosystems. Indeed, less than $160 \mathrm{~km}$ to the south of Andvord Bay, observations of warm modified UCDW intrusions and an invigorated "meltwater pump" present an alternative mechanism for sustaining local primary production (Cape et al., 2019). The scope of our results should be highlighted. If we assume Andvord Bay is representative of a typical cold-based fjord, and

760 similarly, Barilari Bay is representative of a warm-based fjord (6\% MWf at surface, Cape et al. 2019) then we can estimate the glacial meltwater export resulting from a single wind event for the entire western coast of the WAP (see Supplemental Methods). A total of $3.6 \times 10^{10} \mathrm{~m}^{3}\left(36 \mathrm{~km}^{3}\right)$ of surface glacial meltwater is exported seaward, which corresponds to $2.0 \times 10^{6}$ mol dFe. A modelling study estimated a total meltwater discharge for all of Antarctica to be $32.5-97.5 \mathrm{~km}^{3} \mathrm{yr}^{-1}$ (Pattyn 2010). Thus, katabatic winds are highly efficient at delivering surface meltwater produced near the coast to the continental shelves.

765 However, this is small compared to the total basal melt production rate due to warm ocean temperatures for the largest ice shelves. Using highly accurate remote sensing topographic measurements Adusumilli et al. (2020) found that the major ice sheets have a steady-state meltwater production value of $1100 \pm 60 \mathrm{~km}^{3} \mathrm{yr}^{-1}$. In a different modeling study, it was estimated 300 $-800 \mathrm{~km}^{3} \mathrm{yr}^{-1}$ enters the SO accounting for observed trends in SO sea surface temperature, sea ice expansion, and sea surface height (Rye et al. 2020). The WAP feeds most directly into the Antarctic Circumpolar Current (ACC), which advects modified coastal waters downstream to the productive Scotia Sea region. As the next wave of ocean biogeochemical models incorporate processes at the ice-ocean interface, better predictions of Fe supply to the ACC will be made.

In Andvord Bay, primary production will be sensitive to future changes in subglacial discharge as Antarctic glaciers continue to melt in response to oceanic and atmospheric warming (Smith et al., 2020). A greater amount of sediment is expected to be released into the fjord, reducing light quality for primary producers, and as part of a natural tidewater glacier cycle (Brinkerhoff, Truffer and Aschwanden, 2017). This climatic trend is not yet realized within Andvord Bay (Eidam et al., 2019), but is expected to decrease Fe export through increased scavenging and sedimentation, further resembling high-Arctic and temperate fjords (Hopwood et al. 2016). Therefore, a key question outside the scope of this research is how Fe-binding ligand complements will change in the future. To a first approximation, decreased ligand concentrations associated with the 
phytoplankton bloom are expected to reduce efficacy of solubilization of particulate Fe and natural fertilization downstream resulting from this leaky fjord.

\section{Author Contributions}

K.F. designed the study, conducted the analyses and led the writing of the manuscript. L.H. performed numerical dye simulations. R.S., J.R., and K.B. assisted in the preparation of multi-elemental analyses. D.B. provided data for sediment core analyses. L.H., R.S., D.B., M.V., and K.A.B. were involved in discussing the results and their implications, and contributed to the drafting of the manuscript.

\section{Acknowledgments}

The authors would like to thank all participating principle investigators and their affiliates during the NSF FjordEco project (PLR -1443705). Dr. Lauren Manck (University of Montana) assisted with sampling efforts during NBP1603. We would like to thank the captain and crew of R/V Laurence M. Gould and RVIB Nathaniel B. Palmer and United States Antarctic Program 790 contractors. We also thank Dr. Brian Powell (University of Hawai i, Manoa) for helpful comments and for providing resources for the modeling effort. K.F. was supported by a NSF GRF (NSF 15-597).

\section{References}

AF, Z. et al. (2017) 'Glacial dropstones: islands enhancing seafloor species richness of benthic megafauna in West Antarctic Peninsula fjords', Marine Ecology Progress Series, 583, pp. 1-14. Available at: https://www.int-

$795 \mathrm{res} . \mathrm{com} / \mathrm{abstracts} / \mathrm{meps} / \mathrm{v} 583 / \mathrm{p} 1-14 /$.

Alderkamp, A. C. et al. (2012) 'Iron from melting glaciers fuels phytoplankton blooms in the Amundsen Sea (Southern Ocean): Phytoplankton characteristics and productivity', Deep-Sea Research Part II: Topical Studies in Oceanography, 71-76, pp. 3248. doi: 10.1016/j.dsr2.2012.03.005.

Annett, A. L. et al. (2015) 'Comparative roles of upwelling and glacial iron sources in Ryder Bay, coastal western Antarctic 800 Peninsula', Marine Chemistry. doi: 10.1016/j.marchem.2015.06.017.

Annett, A. L. et al. (2017) 'Controls on dissolved and particulate iron distributions in surface waters of the Western Antarctic Peninsula shelf’, Marine Chemistry. doi: 10.1016/j.marchem.2017.06.004.

Armstrong, P. B., Lyons, W. B. and Gaudette, H. E. (1979) 'Application of Formaldoxime Colorimetric Method for the Determination of Manganese in the Pore Water of Anoxic Estuarine Sediments', Estuaries. Coastal and Estuarine Research 805 Federation, 2(3), pp. 198-201. doi: 10.2307/1351736.

Bintanja, R. et al. (2014) 'The future of Antarctica's surface winds simulated by a high-resolution global climate model: 1. 
Model description and validation', Journal of Geophysical Research: Atmospheres. John Wiley \& Sons, Ltd, 119(12), pp. 7136-7159. doi: 10.1002/2013JD020847.

Boyd, P. W. et al. (2019) 'Multi-faceted particle pumps drive carbon sequestration in the ocean', Nature, 568(7752), pp. 327810 335. doi: 10.1038/s41586-019-1098-2.

Boyle, E. A., Edmond, J. M. and Sholkovitz, E. R. (1977) 'The mechanism of iron removal in estuaries', Geochimica et Cosmochimica Acta, 41(9), pp. 1313-1324. doi: http://dx.doi.org/10.1016/0016-7037(77)90075-8.

Brendel, P. J. and Luther, G. W. (1995) 'Development of a Gold Amalgam Voltammetric Microelectrode for the Determination of Dissolved Fe, Mn, O2, and S(-II) in Porewaters of Marine and Freshwater Sediments', Environmental Science and 815 Technology. doi: 10.1021/es00003a024.

Brinkerhoff, D., Truffer, M. and Aschwanden, A. (2017) 'Sediment transport drives tidewater glacier periodicity', Nature Communications, 8(1), p. 90. doi: 10.1038/s41467-017-00095-5.

Buck, K. N. et al. (2018) 'Organic complexation of iron in the eastern tropical South Pacific: Results from US GEOTRACES Eastern Pacific Zonal Transect (GEOTRACES cruise GP16)', Marine Chemistry, 201, pp. 229-241. doi: 820 https://doi.org/10.1016/j.marchem.2017.11.007.

Buck, K. N., Selph, K. E. and Barbeau, K. A. (2010) 'Iron-binding ligand production and copper speciation in an incubation experiment of Antarctic Peninsula shelf waters from the Bransfield Strait, Southern Ocean', Marine Chemistry. doi: 10.1016/j.marchem.2010.06.002.

Buck, K. N., Sohst, B. and Sedwick, P. N. (2015) 'The organic complexation of dissolved iron along the U.S. GEOTRACES

825 (GA03) North Atlantic Section', Deep Sea Research Part II: Topical Studies in Oceanography, 116, pp. 152-165. doi: https://doi.org/10.1016/j.dsr2.2014.11.016.

Burdige, D. J. and Komada, T. (2020) 'Iron redox cycling, sediment resuspension and the role of sediments in low oxygen environments as sources of iron to the water column', Marine Chemistry. doi: 10.1016/j.marchem.2020.103793.

Cape, M. R. et al. (2019) 'Circumpolar Deep Water Impacts Glacial Meltwater Export and Coastal Biogeochemical Cycling 830 Along the West Antarctic Peninsula ', Frontiers in Marine Science , p. 144.

Cook, A. J. et al. (2016) 'Ocean forcing of glacier retreat in the western Antarctic Peninsula', Science, 353(6296), pp. 283 LP - 286. doi: 10.1126/science.aae0017.

Cowan, E. A. and Powell, R. D. (1990) 'Suspended sediment transport and deposition of cyclically interlaminated sediment in a temperate glacial fjord, Alaska, U.S.A.', Geological Society, London, Special Publications, 53(1), pp. 75 LP - 89. doi:

835 10.1144/GSL.SP.1990.053.01.04.

Dale, A. W. et al. (2015) 'A revised global estimate of dissolved iron fluxes from marine sediments', Global Biogeochemical Cycles. John Wiley \& Sons, Ltd, 29(5), pp. 691-707. doi: 10.1002/2014GB005017.

Death, R. et al. (2014) 'Antarctic ice sheet fertilises the Southern Ocean', Biogeosciences. doi: 10.5194/bg-11-2635-2014.

Dierssen, H. M., Smith, R. C. and Vernet, M. (2002) 'Glacial meltwater dynamics in coastal waters west of the Antarctic 840 peninsula', Proceedings of the National Academy of Sciences of the United States of America. doi: 10.1073/pnas.032206999. 
Domack, E. W. and Ishman, S. (1993) 'Oceanographic and physiographic controls on modern sedimentation within Antarctic fjords’, Geological Society of American Bulletin. doi: 10.1130/0016-7606(1993)105<1175:OAPCOM>2.3.CO;2.

Domack, E. W. and Williams, C. R. (2011) 'Fine structure and suspended sediment transport in three Antarctic fjords', in. doi: 10.1029/ar050p0071.

845 van Duren, L. A. and Middelburg, J. J. (2001) 'The benthic boundary layer: Transport processes and biogeochemistry', Eos, Transactions American Geophysical Union. doi: 10.1029/01eo00381.

Egbert, G. D. and Erofeeva, S. Y. (2002) 'Efficient Inverse Modeling of Barotropic Ocean Tides', Journal of Atmospheric and Oceanic Technology, 19(2), pp. 183-204. doi: 10.1175/1520-0426(2002)019<0183:EIMOBO>2.0.CO;2.

Eidam, E. F. et al. (2019) 'Variability of Sediment Accumulation Rates in an Antarctic Fjord', Geophysical Research Letters. 850 doi: $10.1029 / 2019$ GL084499.

Ekern, L. (2017) Assessing Primary Production via nutrient deficits in Andvord Bay, Antarctica 2015-2016. University of California, San Diego.

Fitzsimmons, J. N. et al. (2015) 'The composition of dissolved iron in the dusty surface ocean: An exploration using sizefractionated iron-binding ligands', Marine Chemistry. doi: 10.1016/j.marchem.2014.09.002.

855 Fitzsimmons, J. N. et al. (2017) 'Iron persistence in a distal hydrothermal plume supported by dissolved-particulate exchange', Nature Geoscience, 10(3), pp. 195-201. doi: 10.1038/ngeo2900.

Gerringa, L. J. A. et al. (2015) 'Sources of iron in the Ross Sea polynya in early summer', Marine Chemistry.

Gledhill, M. and Buck, K. N. (2012) 'The organic complexation of iron in the marine environment: a review', Frontiers in microbiology. Frontiers Research Foundation, 3, p. 69. doi: 10.3389/fmicb.2012.00069.

860 Goldberg, T. et al. (2012) 'Controls on Mo isotope fractionations in a Mn-rich anoxic marine sediment, Gullmar Fjord, Sweden', Chemical Geology. doi: 10.1016/j.chemgeo.2011.12.020.

Grange, L. J. and Smith, C. R. (2013) 'Megafaunal communities in rapidly warming fjords along the West Antarctic Peninsula: Hotspots of abundance and beta diversity', PLOS ONE. doi: 10.1371/journal.pone.0077917.

Hahn-Woernle, L. et al. (2020) 'Sensitivity of the summer upper ocean heat content in a Western Antarctic Peninsula fjord', 865 Progress in Oceanography, 183, p. 102287. doi: https://doi.org/10.1016/j.pocean.2020.102287.

Haidvogel, D. B. et al. (2008) 'Ocean forecasting in terrain-following coordinates: Formulation and skill assessment of the Regional Ocean Modeling System', Journal of Computational Physics, 227(7), pp. 3595-3624. doi: https://doi.org/10.1016/j.jcp.2007.06.016.

Halbach, L. et al. (2019) 'Tidewater Glaciers and Bedrock Characteristics Control the Phytoplankton Growth Environment in 870 a Fjord in the Arctic ', Frontiers in Marine Science, , p. 254. Available at: https://www.frontiersin.org/article/10.3389/fmars.2019.00254.

Hawkings, J. R. et al. (2014) 'Ice sheets as a significant source of highly reactive nanoparticulate iron to the oceans.', Nature communications, 5(May), p. 3929. doi: 10.1038/ncomms4929.

Hawkings, J. R. et al. (2018) 'The silicon cycle impacted by past ice sheets', Nature Communications, 9(1), p. 3210. doi: 
Hawkings, J. R. et al. (2020) 'Enhanced trace element mobilization by Earth's ice sheets', Proceedings of the National Academy of Sciences, 117(50), pp. 31648 LP - 31659. doi: 10.1073/pnas.2014378117.

Hodson, A. et al. (2017) 'Climatically sensitive transfer of iron to maritime Antarctic ecosystems by surface runoff'. The Author(s), 8, p. 14499.

880 Hogle, S. L. et al. (2016) 'Copiotrophic marine bacteria are associated with strong iron-binding ligand production during phytoplankton blooms', Limnology and Oceanography Letters. John Wiley \& Sons, Ltd, 1(1), pp. 36-43. doi: https://doi.org/10.1002/lol2.10026.

Hopwood, M. J. et al. (2015) 'Glacial meltwater from Greenland is not likely to be an important source of Fe to the North Atlantic', Biogeochemistry, 124(1), pp. 1-11. doi: 10.1007/s10533-015-0091-6.

885 Hopwood, M. J. et al. (2016) 'Seasonal changes in Fe along a glaciated Greenlandic fjord. ', Frontiers in Earth Science , 4(March), pp. 1-13. doi: 10.3389/feart.2016.00015.

Hopwood, M. J. et al. (2019) 'Highly variable iron content modulates iceberg-ocean fertilisation and potential carbon export', Nature Communications, 10(1), p. 5261. doi: 10.1038/s41467-019-13231-0.

Hudson, R. J. M., Rue, E. L. and Bruland, K. W. (2003) 'Modeling Complexometric Titrations of Natural Water Samples',

890 Environmental Science \& Technology. American Chemical Society, 37(8), pp. 1553-1562. doi: 10.1021/es025751a.

Jack Pan, B. et al. (2019) 'The optical and biological properties of glacial meltwater in an Antarctic fjord', PLoS ONE. doi: 10.1371/journal.pone.0211107.

Jackson, R. H., Straneo, F. and Sutherland, D. A. (2014) 'Externally forced fluctuations in ocean temperature at Greenland glaciers in non-summer months', Nature Geoscience, 7(7), pp. 503-508. doi: 10.1038/ngeo2186.

895 De Jong, J. T. M. et al. (2015) 'Sources and fluxes of dissolved iron in the Bellingshausen Sea (West Antarctica): The importance of sea ice, icebergs and the continental margin', Marine Chemistry, 177, pp. 518-535. doi: https://doi.org/10.1016/j.marchem.2015.08.004.

King, A. L. and Barbeau, K. A. (2011) 'Dissolved iron and macronutrient distributions in the southern California Current System', Journal of Geophysical Research: Oceans. John Wiley \& Sons, Ltd, 116(C3). doi: 10.1029/2010JC006324.

900 Lagerström, M. E. et al. (2013) 'Automated on-line flow-injection ICP-MS determination of trace metals ( $\mathrm{Mn}, \mathrm{Fe}, \mathrm{Co}, \mathrm{Ni}, \mathrm{Cu}$ and $\mathrm{Zn}$ ) in open ocean seawater: Application to the GEOTRACES program', Marine Chemistry, 155, pp. 71-80. doi: https://doi.org/10.1016/j.marchem.2013.06.001.

Li, M. et al. (2014) 'Microbial iron uptake as a mechanism for dispersing iron from deep-sea hydrothermal vents', Nature Communications, 5(1), p. 3192. doi: 10.1038/ncomms4192.

905 Lohan, M. C., Aguilar-Islas, A. M. and Bruland, K. W. (2006) 'Direct determination of iron in acidified (pH 1.7) seawater samples by flow injection analysis with catalytic spectrophotometric detection: Application and intercomparison', Limnology and Oceanography: Methods. John Wiley \& Sons, Ltd, 4(6), pp. 164-171. doi: 10.4319/lom.2006.4.164.

Lundesgaard, Ø. et al. (2019) 'Response of an antarctic Peninsula fjord to summer Katabatic wind events', Journal of Physical 
Oceanography. doi: 10.1175/JPO-D-18-0119.1.

910 Lundesgaard, Ø. et al. (2020) 'Hydrography and energetics of a cold subpolar fjord: Andvord Bay, western Antarctic Peninsula', Progress in Oceanography. doi: 10.1016/j.pocean.2019.102224.

Luther, G. W. et al. (2008) 'Use of voltammetric solid-state (micro)electrodes for studying biogeochemical processes: Laboratory measurements to real time measurements with an in situ electrochemical analyzer (ISEA)', Marine Chemistry, 108(3), pp. 221-235. doi: https://doi.org/10.1016/j.marchem.2007.03.002.

915 Luther III, G. W. et al. (1998) 'Simultaneous measurement of O2, Mn, Fe, I-, and S(-II) in marine pore waters with a solidstate voltammetric microelectrode', Limnology and Oceanography. John Wiley \& Sons, Ltd, 43(2), pp. 325-333. doi: https://doi.org/10.4319/10.1998.43.2.0325.

Marsay, C. M. et al. (2014) 'Estimating the benthic efflux of dissolved iron on the Ross Sea continental shelf', Geophysical Research Letters. doi: 10.1002/2014GL061684.

920 Meire, L. et al. (2017) 'Marine-terminating glaciers sustain high productivity in Greenland fjords', Global Change Biology, 23(12), pp. 5344-5357. doi: 10.1111/gcb.13801.

Meredith, M. P. et al. (2017) 'Changing distributions of sea ice melt and meteoric water west of the Antarctic Peninsula', Deep Sea Research Part II: Topical Studies in Oceanography, 139, pp. 40-57. doi: https://doi.org/10.1016/j.dsr2.2016.04.019.

Mikucki, J. A. et al. (2009) 'A Contemporary Microbially Maintained Subglacial Ferrous \&quot;Ocean\&quot'; Science, 925 324(5925), pp. 397 LP - 400. doi: 10.1126/science.1167350.

Moffat, C. et al. (2008) 'A first description of the Antarctic Peninsula Coastal Current', Deep Sea Research Part II: Topical Studies in Oceanography, 55(3), pp. 277-293. doi: https://doi.org/10.1016/j.dsr2.2007.10.003.

Mouginot, J. et al. (2019) 'Forty-six years of Greenland Ice Sheet mass balance from 1972 to 2018', Proceedings of the National Academy of Sciences, 116(19), pp. 9239 LP - 9244. doi: 10.1073/pnas.1904242116.

$930 \mathrm{Ng}$, H. C. et al. (2020) 'Sediment efflux of silicon on the Greenland margin and implications for the marine silicon cycle', Earth and Planetary Science Letters, 529, p. 115877. doi: https://doi.org/10.1016/j.eps1.2019.115877.

Oliver, H. et al. (2019) 'Modeling Iron and Light Controls on the Summer Phaeocystis antarctica Bloom in the Amundsen Sea Polynya', Global Biogeochemical Cycles. John Wiley \& Sons, Ltd, 33(5), pp. 570-596. doi: 10.1029/2018GB006168.

Omanović, D., Garnier, C. and Pižeta, I. (2015) 'ProMCC: An all-in-one tool for trace metal complexation studies', Marine 935 Chemistry, 173, pp. 25-39. doi: https://doi.org/10.1016/j.marchem.2014.10.011.

Pan, B. J. et al. (2020) 'Environmental drivers of phytoplankton taxonomic composition in an Antarctic fjord', Progress in Oceanography. doi: 10.1016/j.pocean.2020.102295.

Person, R. et al. (2019) 'Sensitivity of ocean biogeochemistry to the iron supply from the Antarctic Ice Sheet explored with a biogeochemical model', Biogeosciences. doi: 10.5194/bg-16-3583-2019.

940 Poulton, S. W. and Canfield, D. E. (2005) 'Development of a sequential extraction procedure for iron: implications for iron partitioning in continentally derived particulates', Chemical Geology, 214(3), pp. 209-221. doi: https://doi.org/10.1016/j.chemgeo.2004.09.003. 
Pritchard, H. D. and Vaughan, D. G. (2007) 'Widespread acceleration of tidewater glaciers on the Antarctic Peninsula', Journal of Geophysical Research: Earth Surface. John Wiley \& Sons, Ltd, 112(F3). doi: 10.1029/2006JF000597.

945 Raiswell, R. et al. (2018) 'Iron in Glacial Systems: Speciation, Reactivity, Freezing Behavior, and Alteration During Transport', Frontiers in Earth Science. doi: 10.3389/feart.2018.00222.

Raiswell, R. and Canfield, D. E. (2012) 'The Iron Biogeochemical Cycle Past and Present', Geochemical Perspectives, pp. 1220. doi: 10.7185/geochempersp.1.1.

Rignot, E. et al. (2013) 'Ice-Shelf Melting Around Antarctica', Science, 341(6143), pp. 266 LP - 270. doi: $950 \quad 10.1126 /$ science. 1235798.

Rudnick, R. L. and Gao, S. (2013) 'Composition of the Continental Crust', in Treatise on Geochemistry: Second Edition. doi: 10.1016/B978-0-08-095975-7.00301-6.

Schlosser, C. et al. (2018) 'Mechanisms of dissolved and labile particulate iron supply to shelf waters and phytoplankton blooms off South Georgia, Southern Ocean', Biogeosciences. Copernicus Publications, 15(16), pp. 4973-4993. doi: 955 10.5194/bg-15-4973-2018.

Schodlok, M. P., Menemenlis, D. and Rignot, E. J. (2016) 'Ice shelf basal melt rates around Antarctica from simulations and observations', Journal of Geophysical Research: Oceans. doi: 10.1002/2015JC011117.

Schroth, A. W. et al. (2014) 'Estuarine removal of glacial iron and implications for iron fluxes to the ocean', Geophysical Research Letters, 41(11), pp. 3951-3958. doi: 10.1002/2014GL060199.

960 Severmann, S. et al. (2010) 'The continental shelf benthic iron flux and its isotope composition', Geochimica et Cosmochimica Acta, 74(14), pp. 3984-4004. doi: https://doi.org/10.1016/j.gca.2010.04.022.

Sherrell, R. M. et al. (2018) "A "shallow bathtub ring” of local sedimentary iron input maintains the Palmer Deep biological hotspot on the West Antarctic Peninsula shelf', Philosophical Transactions of the Royal Society A: Mathematical, Physical and Engineering Sciences. doi: 10.1098/rsta.2017.0171.

965 Smith, B. et al. (2020) 'Pervasive ice sheet mass loss reflects competing ocean and atmosphere processes', Science, p. eaaz5845. doi: 10.1126/science.aaz5845.

St-Laurent, P. et al. (2017) 'Pathways and supply of dissolved iron in the Amundsen Sea (Antarctica)', Journal of Geophysical Research: Oceans. John Wiley \& Sons, Ltd, 122(9), pp. 7135-7162. doi: 10.1002/2017JC013162.

St-Laurent, P. et al. (2019) 'Modeling the Seasonal Cycle of Iron and Carbon Fluxes in the Amundsen Sea Polynya, 970 Antarctica', Journal of Geophysical Research: Oceans. doi: 10.1029/2018JC014773.

Straneo, F. and Cenedese, C. (2015) 'The Dynamics of Greenland's Glacial Fjords and Their Role in Climate', Annual Review of Marine Science. doi: 10.1146/annurev-marine-010213-135133.

Tagliabue, A. et al. (2019) 'The interplay between regeneration and scavenging fluxes drives ocean iron cycling', Nature Communications, 10(1), p. 4960. doi: 10.1038/s41467-019-12775-5.

975 Taylor, R. S., DeMaster, D. J. and Burdige, D. J. (2020) 'Assessing the distribution of labile organic carbon from diverse depositional environments on the West Antarctic Peninsula shelf', Deep Sea Research Part I: Oceanographic Research 
Papers, 156, p. 103166. doi: https://doi.org/10.1016/j.dsr.2019.103166.

Taylor, S. R. and McLennan, S. M. (1995) 'The geochemical evolution of the continental crust', Reviews of Geophysics. John Wiley \& Sons, Ltd, 33(2), pp. 241-265. doi: 10.1029/95RG00262.

980 Thuróczy, C.-E. et al. (2011) 'Distinct trends in the speciation of iron between the shallow shelf seas and the deep basins of the Arctic Ocean', Journal of Geophysical Research: Oceans. John Wiley \& Sons, Ltd, 116(C10). doi: 10.1029/2010JC006835.

Thuróczy, C. E. et al. (2012) 'Key role of organic complexation of iron in sustaining phytoplankton blooms in the Pine Island and Amundsen Polynyas (Southern Ocean)', Deep-Sea Research Part II: Topical Studies in Oceanography. doi: 985 10.1016/j.dsr2.2012.03.009.

Twining, B. S. et al. (2004) 'Cellular iron contents of plankton during the Southern Ocean Iron Experiment (SOFeX)', DeepSea Research Part I: Oceanographic Research Papers. doi: 10.1016/j.dsr.2004.08.007.

Vernet, M. et al. (2008) 'Primary production within the sea-ice zone west of the Antarctic Peninsula: I-Sea ice, summer mixed layer, and irradiance', Deep-Sea Research Part II: Topical Studies in Oceanography. doi: 10.1016/j.dsr2.2008.05.021.

990 Wagener, P., Schwenke, A. and Barcikowski, S. (2012) 'How Citrate Ligands Affect Nanoparticle Adsorption to Microparticle Supports', Langmuir. American Chemical Society, 28(14), pp. 6132-6140. doi: 10.1021/la204839m.

van Wessem, J. M. et al. (2014) 'Updated cloud physics in a regional atmospheric climate model improves the modelled surface energy balance of Antarctica', The Cryosphere. Copernicus Publications, 8(1), pp. 125-135. doi: 10.5194/tc-8-1252014.

$995 \mathrm{Wu}$, J. et al. (2001) 'Soluble and colloidal iron in the oligotrophic North Atlantic and North Pacific', Science. American Association for the Advancement of Science, 293(5531), pp. 847-849.

Zhang, R. et al. (2015) 'Transport and reaction of iron and iron stable isotopes in glacial meltwaters on Svalbard near Kongsfjorden: From rivers to estuary to ocean', Earth and Planetary Science Letters, 424, pp. 201-211.

Ziegler, A. F. et al. (2020) 'Intense deposition and rapid processing of seafloor phytodetritus in a glaciomarine fjord, Andvord

Bay (Antarctica)', Progress in Oceanography, 187, p. 102413. doi: https://doi.org/10.1016/j.pocean.2020.102413. 


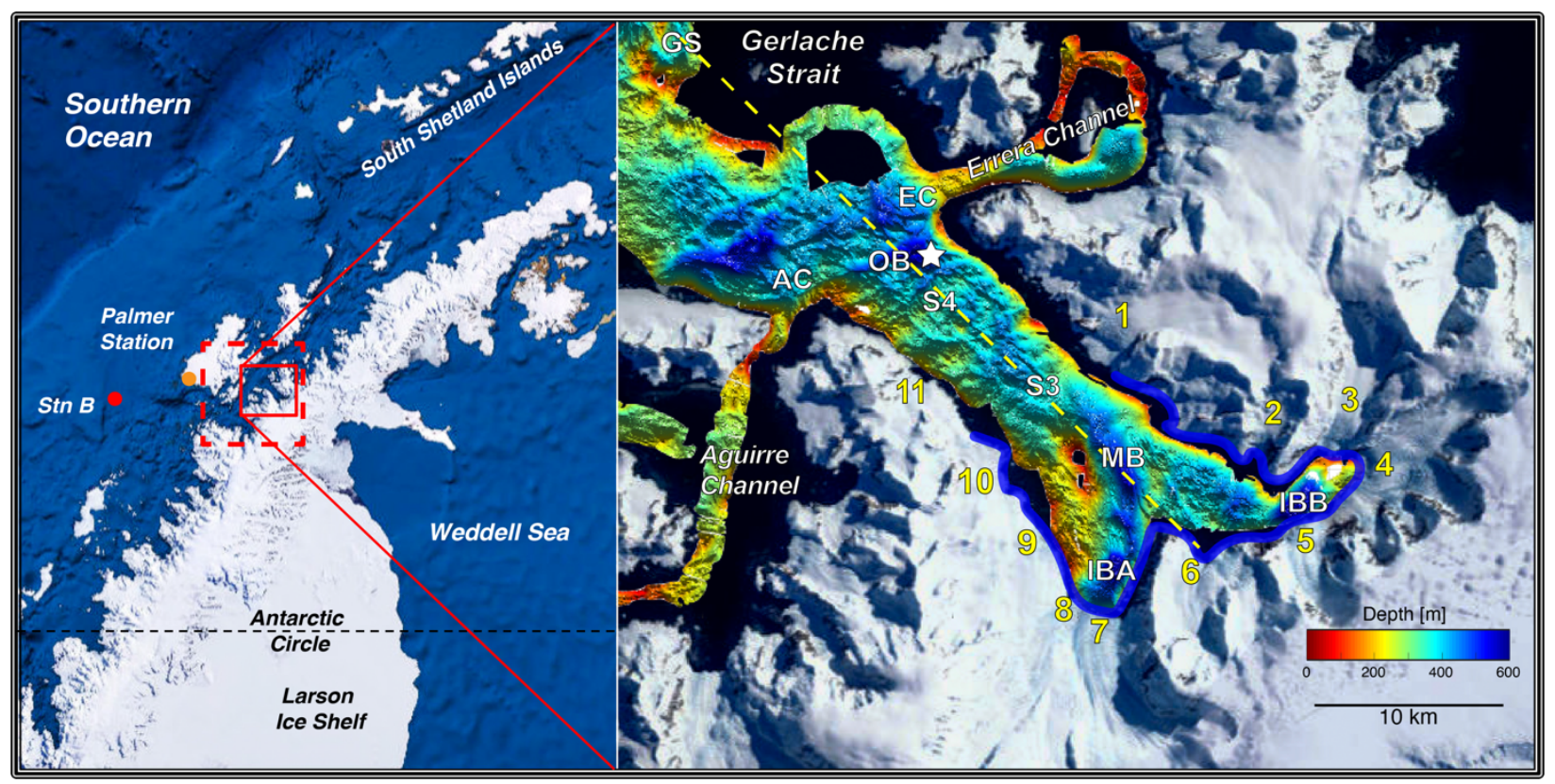

1005 Figure 1. Regional map of study region (red box, inset right) and model domain (dashed red box) with nearby Palmer Station and shelf station (Stn B). Bathymetric map of Andvord Bay with important stations labeled (GS = Gerlache Strait, AC = Aguirre Channel, EC = Errera Channel, OB = Outer Basin, S4 = Sill 4, S3 = Sill 3, MB = Middle Basin, IBA = Inner Basin A, IBB = Inner Basin B) and the surrounding tidewater glaciers numbered $(4=$ Moser Glacier, $7=$ Bagshawe Glacier $)$. The locations for sediment cores collected in January 2016 and included in this study are indicated by the star. The dashed yellow line indicates the transect along which vertical sections are plotted. Blue outline (inset right) shows glacial fronts where meltwater is introduced in the model. 


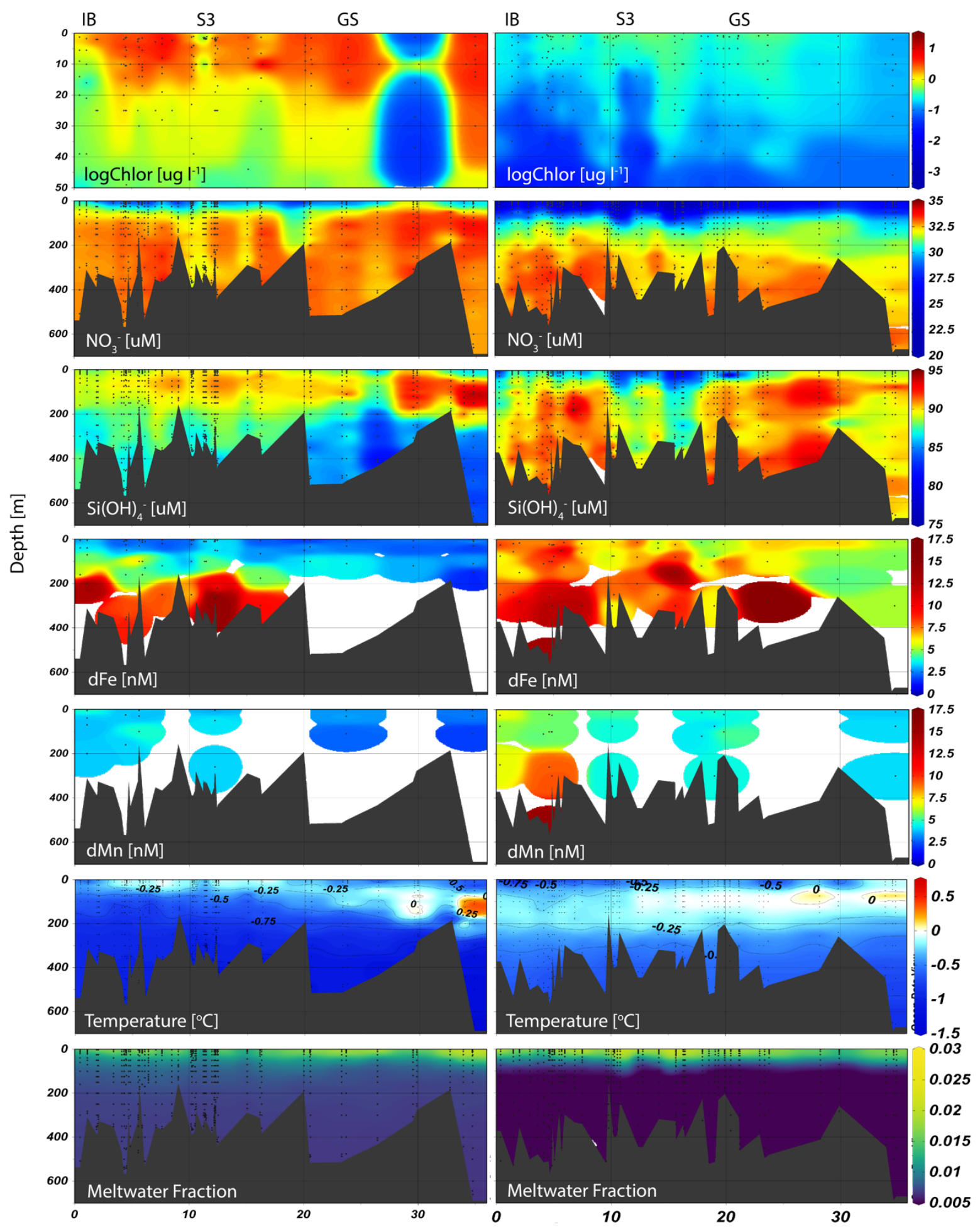

Distance from Bagshawe Glacier [km] 
Figure 2. Seasonal phytoplankton, macro-, micronutrient, temperature, and meltwater distributions plotted as sections extending from the inner basin (IBA, left) towards Gerlache Strait (GS, right). Plots were made with Ocean Data View visualization software.

December $2015 \quad$ April 2016
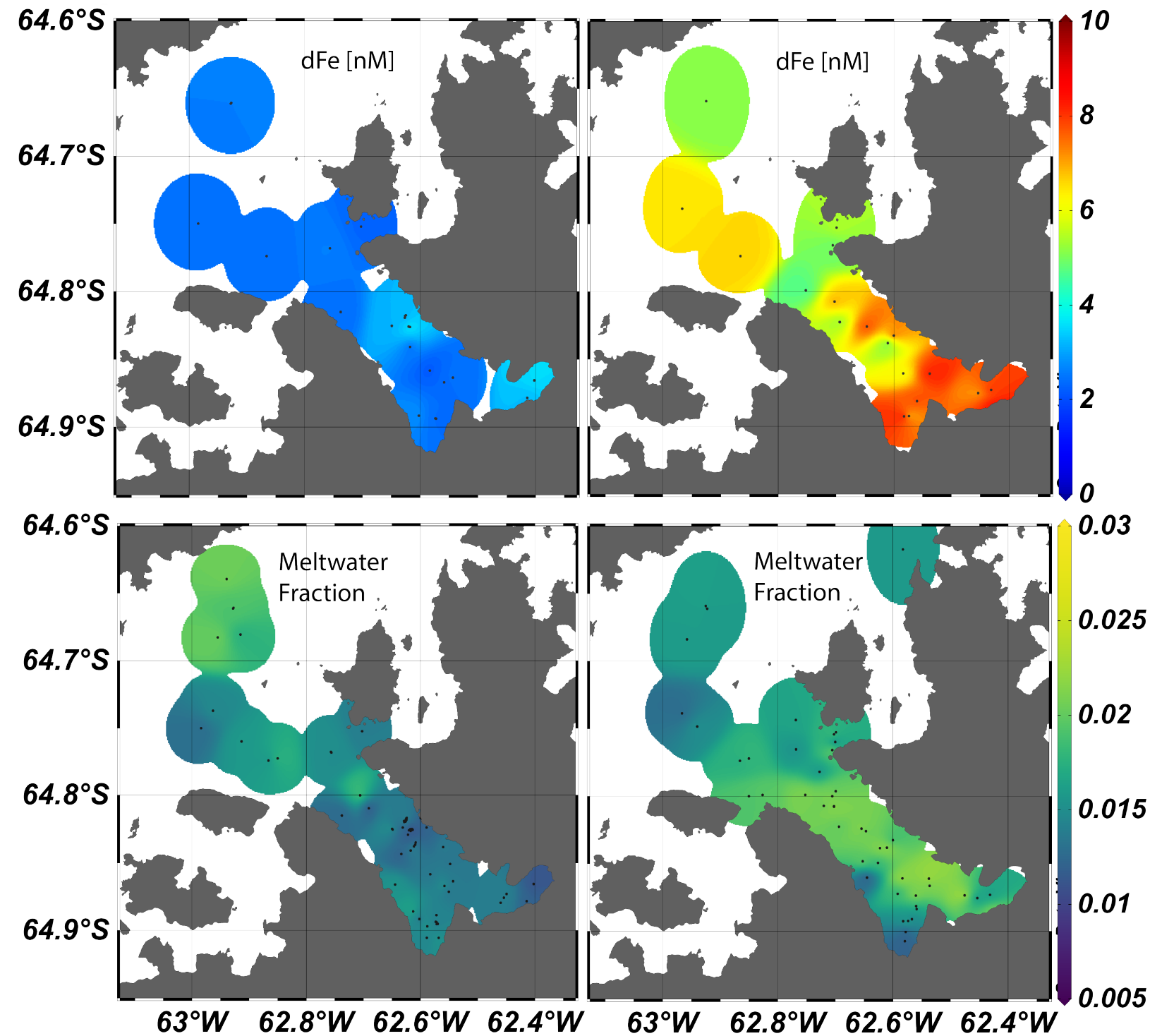

Figure 3. Surface (<20m) dissolved Fe (top) and meltwater fraction (bottom) for late-Spring (left two panels) and Fall (right two panels). 

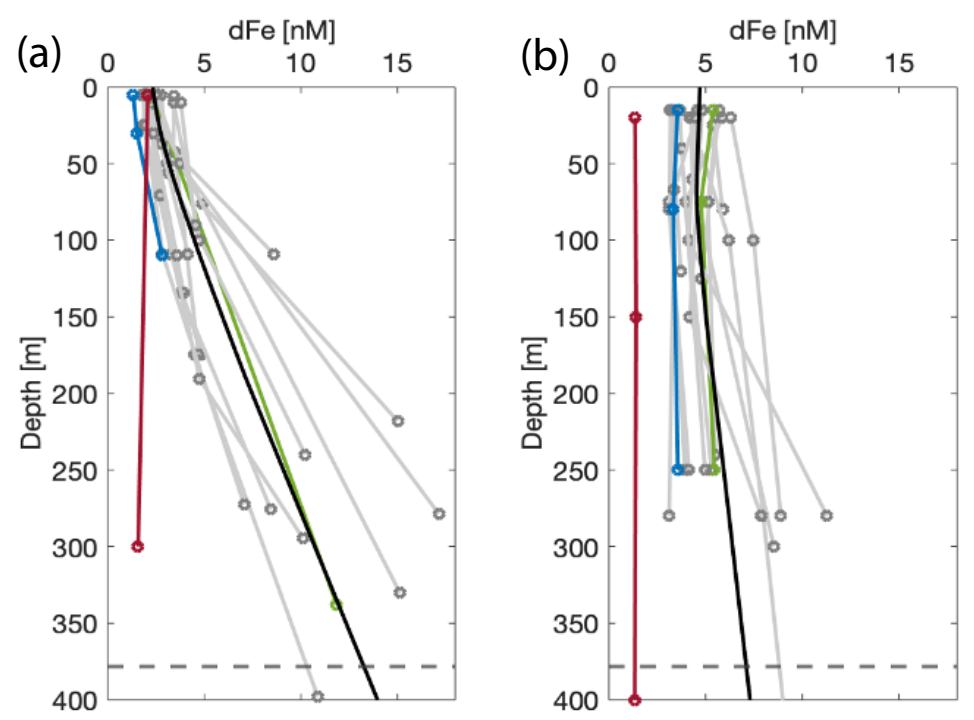

Figure 4. Depth profiles of dissolved Fe [nM] sampled in the Andvord Bay region for December 2015 (A) and April 2016 (B). The 1020 colored lines indicate highlighted profiles: the geometric mean of the linearly interpolated data points within Andvord Bay (black), Station B on the continental shelf (red, see Fig. 1), Station GS (Gerlache Strait, blue) and Station S3 (green). Other Andvord Bay stations are shown in grey. 

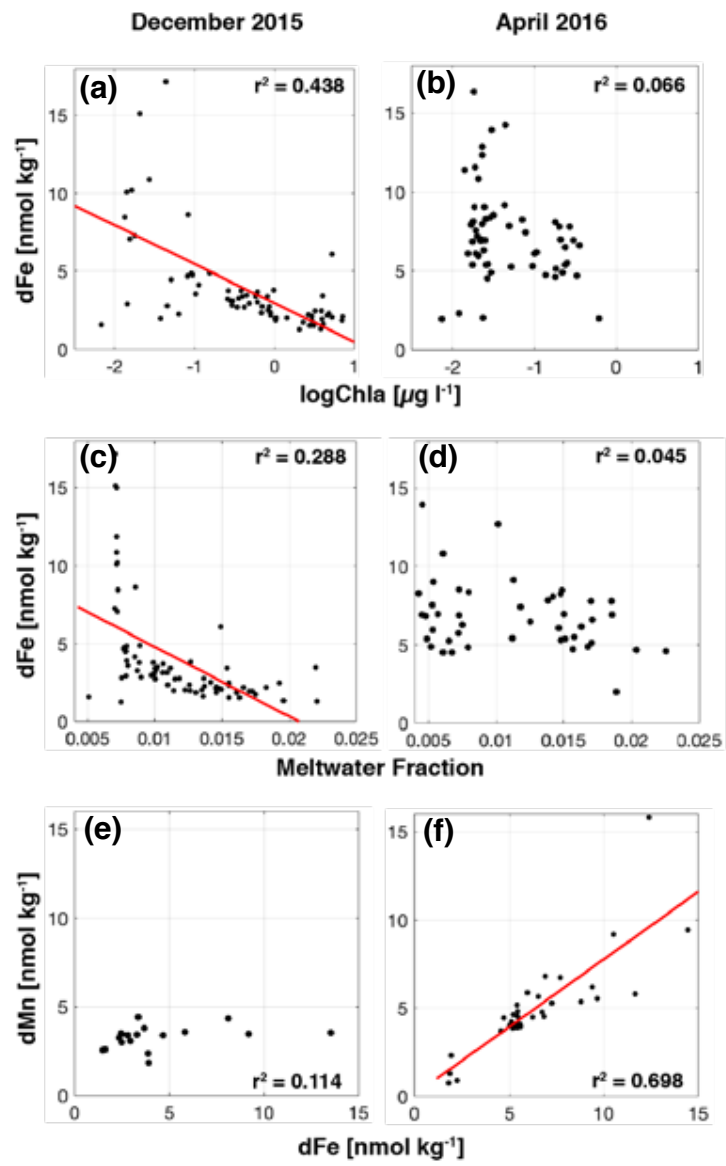

Figure 5. Dissolved trace metals plotted against observed and derived variables for December 2015 (a, c, e) and April 2016 (b, d, f). Dissolved Fe (a-b) versus logChlorophyll-a concentrations. Dissolved Fe (c-d) versus meltwater fraction. Dissolved Mn (e-f) versus dissolved Fe. Least-squares regression lines are shown where they are statistically significant $(p<0.005)$. 

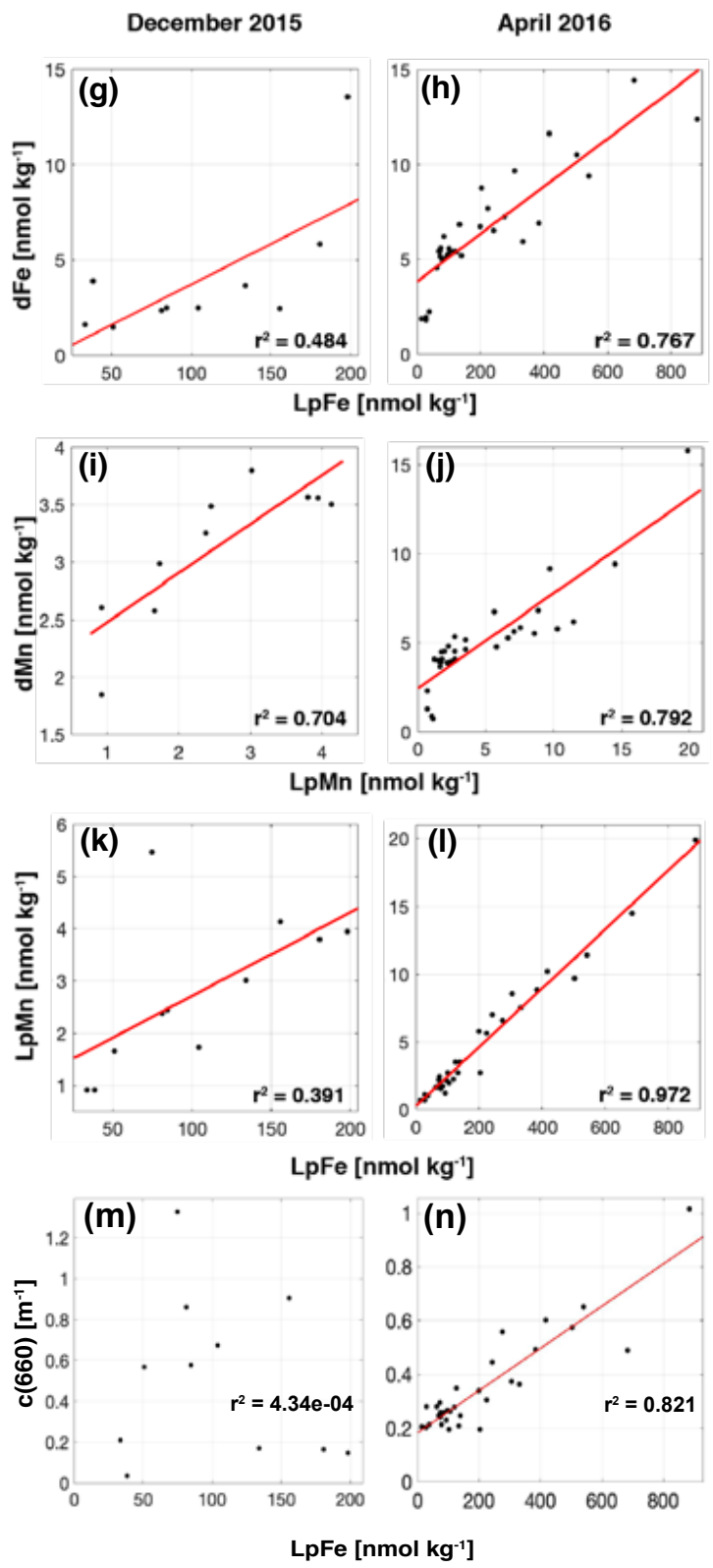

Figure 5 (cont'd). Dissolved Fe and Mn concentrations versus labile particulate Fe and Mn for each season. Dissolved Fe (g-h), labile particulate Mn (k-l), and beam attenuation coefficient (m-n) versus labile particulate Fe. Dissolved Mn (i-j) versus labile particulate Mn. Least-squares regression lines are shown where they are statistically significant $(p<0.005)$. 


\begin{tabular}{|c|c|c|c|c|c|c|c|c|c|c|c|c|c|c|}
\hline Sample Type & Cruise & Location & & $\begin{array}{c}\mathrm{dFe} \\
{[\mathrm{nmol} \mathrm{kg-1]}}\end{array}$ & $\begin{array}{c}\text { TDFe } \\
\text { [nmol kg-1] }\end{array}$ & $\begin{array}{c}\text { TpFe } \\
{[\mathrm{nmol} L-1]}\end{array}$ & $\begin{array}{c}\mathrm{dMn} \\
{[\mathrm{nmol} \mathrm{kg-1]}}\end{array}$ & $\begin{array}{c}\text { TDMn } \\
\text { [nmol kg-1] }\end{array}$ & $\begin{array}{c}\text { TpMn } \\
{[\mathrm{nmol} L-1]}\end{array}$ & dFe:LpFe & $\mathrm{dFe}: \mathrm{TpFe}$ & $\begin{array}{l}\text { LpMn:LpFe } \\
\text { [mol:mol] }\end{array}$ & $\begin{array}{l}\text { TpMn:TpFe } \\
\text { [mol:mol] }\end{array}$ & Description \\
\hline & & & & & & & & & & & & $(0.017)$ & $(0.017)$ & Crustal averages \\
\hline $\begin{array}{l}\text { Glacial } \\
\text { Ice } 1\end{array}$ & LMG1510 & $\begin{array}{c}\text { Inner } \\
\text { Basin A }\end{array}$ & & 211.59 & 122228.21 & 366332.00 & 144.85 & 7359.13 & 10187.59 & $0.17 \%$ & $0.1 \%$ & 0.059 & 0.028 & floating \\
\hline $\begin{array}{l}\text { Glacial } \\
\text { Ice } 2\end{array}$ & LMG1510 & $\begin{array}{c}\text { Inner } \\
\text { Basin A }\end{array}$ & & n.a. & 994.26 & 13036.31 & n.a. & 61.55 & 434.61 & n.a. & n.a. & 0.062 & 0.033 & floating \\
\hline $\begin{array}{l}\text { Glacial } \\
\text { Ice } 3\end{array}$ & NBP1603 & $\begin{array}{l}\text { Neko } \\
\text { Harbor }\end{array}$ & & 1.43 & n.a. & 56.36 & 1.62 & n.a. & 1.41 & n.a. & $2.5 \%$ & n.a. & 0.025 & floating \\
\hline \multirow{3}{*}{$\begin{array}{l}\text { Glacial } \\
\text { Ice } 4\end{array}$} & NBP1603 & $\begin{array}{l}\text { Neko } \\
\text { Harbor }\end{array}$ & & 1.52 & n.a. & 52.75 & 1.81 & n.a. & 1.26 & n.a. & $2.9 \%$ & n.a. & 0.024 & floating \\
\hline & & & AVG & 71.52 & 61611.24 & 94869.36 & 49.43 & 3710.34 & 2656.22 & $0.17 \%$ & $1.8 \%$ & 0.061 & 0.028 & \\
\hline & & & STDEV & 121.31 & 69994.45 & 181078.54 & 82.64 & 5160.17 & 5025.07 & & $1.5 \%$ & 0.002 & 0.004 & \\
\hline $\begin{array}{l}\text { Plume } \\
19 \quad 100 \mathrm{~m}\end{array}$ & NBP1603 & $\begin{array}{c}\text { Inner } \\
\text { Basin A }\end{array}$ & & 11.64 & 419.89 & 402.26 & 5.82 & 15.73 & 9.169 & $2.9 \%$ & $2.9 \%$ & 0.024 & 0.023 & seawater \\
\hline $\begin{array}{l}\text { Plume } \\
20 \_100 \mathrm{~m}\end{array}$ & NBP1603 & $\begin{array}{c}\text { Inner } \\
\text { Basin A }\end{array}$ & & 9.40 & 538.34 & 514.90 & 6.22 & 17.29 & 11.73 & $1.8 \%$ & $1.8 \%$ & 0.021 & 0.023 & seawater \\
\hline $\begin{array}{l}\text { Plume } \\
26 \_110 \mathrm{~m}\end{array}$ & NBP1603 & $\begin{array}{l}\text { Inner } \\
\text { Basin A }\end{array}$ & & 7.26 & 227.24 & 330.37 & 5.28 & 11.63 & 7.665 & $2.7 \%$ & $2.2 \%$ & 0.024 & 0.023 & seawater \\
\hline \multirow[t]{3}{*}{$\begin{array}{l}\text { Plume } \\
27 \_110 \mathrm{~m}\end{array}$} & NBP1603 & $\begin{array}{c}\text { Inner } \\
\text { Basin A }\end{array}$ & & 6.72 & 202.35 & n.a. & 4.79 & 10.36 & n.a. & $3.4 \%$ & n.a. & 0.028 & n.a. & seawater \\
\hline & & & AVG & 8.75 & 346.95 & 415.84 & 5.52 & 13.75 & 9.52 & $2.7 \%$ & $2.3 \%$ & 0.024 & 0.023 & \\
\hline & & & STDEV & 2.25 & 160.40 & 93.01 & 0.62 & 3.29 & 2.05 & $0.7 \%$ & $0.5 \%$ & 0.003 & 0.0002 & \\
\hline
\end{tabular}

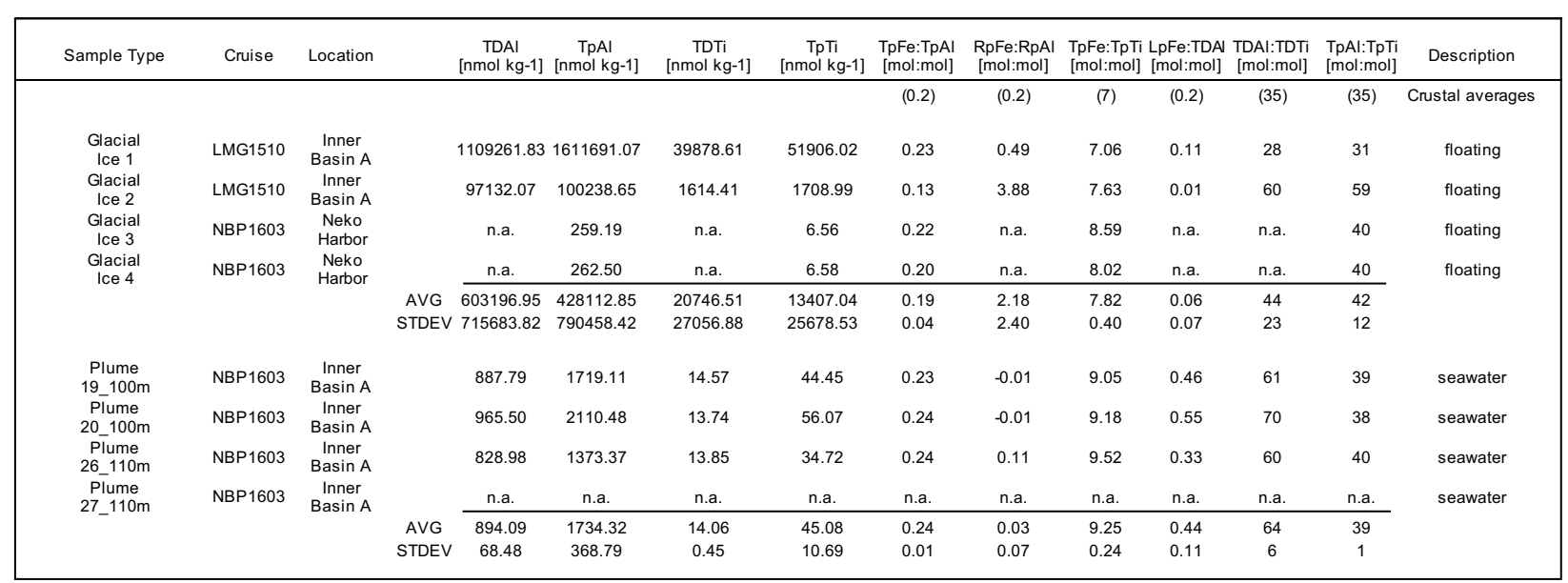

Table 1. Glacial ice and seawater samples analyzed for dissolved, labile, and total particulate trace metals. Crustal averages from Taylor and McClellen (1995): Mn:Fe (0.017 mol:mol), Fe:Al (0.2), and Al:Ti (35). 


\begin{tabular}{|c|c|c|c|c|c|c|c|c|c|c|c|c|}
\hline & Station & $\begin{array}{l}\text { Depth } \\
\text { [m] }\end{array}$ & $\begin{array}{l}\mathrm{dFe} \\
{[\mathrm{nM}]}\end{array}$ & $\begin{array}{l}\mathrm{Fe}^{\prime} \\
{[\mathrm{pM}]}\end{array}$ & $\begin{array}{c}\mathrm{L}_{\mathrm{t}} \\
{[\mathrm{nM}]}\end{array}$ & $+1-$ & $\log K$ & $+/-$ & $\begin{array}{c}\mathrm{el} \\
{[\mathrm{nM}]}\end{array}$ & $\mathrm{L}: \mathrm{dFe}$ & $\log \alpha_{\mathrm{FeL}}$ & $\mathbf{R}_{\mathrm{Ee}}$ \\
\hline \multirow{9}{*}{$\begin{array}{c}\text { December } \\
2015 \\
\text { (LMG1510) }\end{array}$} & IBA & 6 & 1.85 & 0.62 & 4.06 & 1.74 & 12.13 & 0.69 & 2.21 & 2.2 & 12.5 & \\
\hline & IBA & 160 & 5.84 & 5.66 & 8.18 & 0.57 & 11.63 & 0.2 & 2.34 & 1.4 & 12 & \\
\hline & IBB & 6 & 3.36 & 1.19 & 6.22 & 0.52 & 11.99 & 0.14 & 2.86 & 1.9 & 12.4 & \\
\hline & MBA & 8 & 2.12 & 4.7 & 2.82 & 0.37 & 11.58 & 0.2 & 0.69 & 1.3 & 11.4 & \\
\hline & S3 & 11 & 3.41 & 0.79 & 7.27 & 1.97 & 12.05 & 0.44 & 3.85 & 2.1 & 12.6 & \\
\hline & S4 & 7 & 2.01 & 2.39 & 5 & 1.22 & 11.44 & 0.33 & 2.99 & 2.5 & 11.9 & \\
\hline & S4 & 175 & 4.76 & 5.95 & 5.05 & 1.06 & 10.9 & 0.28 & 0.29 & 1.1 & 10.4 & \\
\hline & GS & 6 & 1.53 & 6.2 & 2.26 & 0.33 & 11 & 0.14 & 0.73 & 1.5 & 10.9 & \\
\hline & OBB & 6 & 2.5 & 1.16 & 5.72 & 2.21 & 11.82 & 0.44 & 3.22 & 2.3 & 12.3 & \\
\hline \multirow{12}{*}{$\begin{array}{l}\text { April } 2016 \\
\text { (NBP1603) }\end{array}$} & IBA & 25 & 7.8 & 1.15 & 15.42 & 2.82 & 11.95 & 0.26 & 7.62 & 2 & 12.8 & $85 \%$ \\
\hline & IBA & 110 & 6.72 & 7.18 & 8.54 & 0.88 & 11.69 & 0.35 & 1.82 & 1.3 & 12 & \\
\hline & IBA & 280 & 14.45 & 1.82 & 17.44 & 1.12 & 12.42 & 0.37 & 2.99 & 1.2 & 12.8 & \\
\hline & IBA & 80 & 8.51 & 3.86 & 17.62 & 3.57 & 11.38 & 0.27 & 9.11 & 2.1 & 12.3 & \\
\hline & IBB & 20 & 6.89 & 4.16 & 11.18 & 1.39 & 11.58 & 0.26 & 4.29 & 1.6 & 12.2 & $249 \%$ \\
\hline & IBB & 75 & 5.94 & 3.64 & 14.03 & 1.57 & 11.3 & 0.13 & 8.09 & 2.4 & 12.2 & \\
\hline & MBA & 20 & 4.25 & 18.7 & 13.32 & 4.08 & 10.37 & 0.25 & 9.07 & 3.1 & 11.3 & $297 \%$ \\
\hline & S3 & 15 & 5.41 & 15.67 & 15.33 & 2.18 & 11.54 & 0.14 & 9.92 & 3 & 12.5 & $1883 \%$ \\
\hline & $\begin{array}{c}\text { S4 } \\
\text { Fjord }\end{array}$ & 25 & 6.93 & 4.63 & 15.4 & 3.11 & 11.2 & 0.24 & 8.47 & 2.2 & 12.1 & $94 \%$ \\
\hline & Mouth & 15 & 4.69 & 10.05 & 6.29 & 1.29 & 11.43 & 0.55 & 1.6 & 1.3 & 11.6 & \\
\hline & Mouth & 120 & 5.37 & 6.56 & 7.34 & 1.87 & 11.6 & 0.68 & 1.97 & 1.4 & 11.9 & \\
\hline & GS & 15 & 5.14 & 6.82 & 12 & 2.94 & 11.03 & 0.32 & 6.86 & 2.3 & 11.9 & $10 \%$ \\
\hline
\end{tabular}

Table 2. Ligand concentrations and equilibrium constants detected in seawater samples. Fe' is the free (unbound) iron concentration. $L_{t}$ is the total ligand concentration. $\operatorname{logK}$ is the conditional stability constant. $e L$ is the excess ligand concentration $\left(e L=L_{t}-[d F e]\right)$. $\log \alpha_{\mathrm{FeL}}$, is the complexation capacity. $\mathrm{R}_{\mathrm{FeL}}$, is the ratio of $\mathrm{Fe}$ ' of reoccupied stations, expressed as a percentage. 


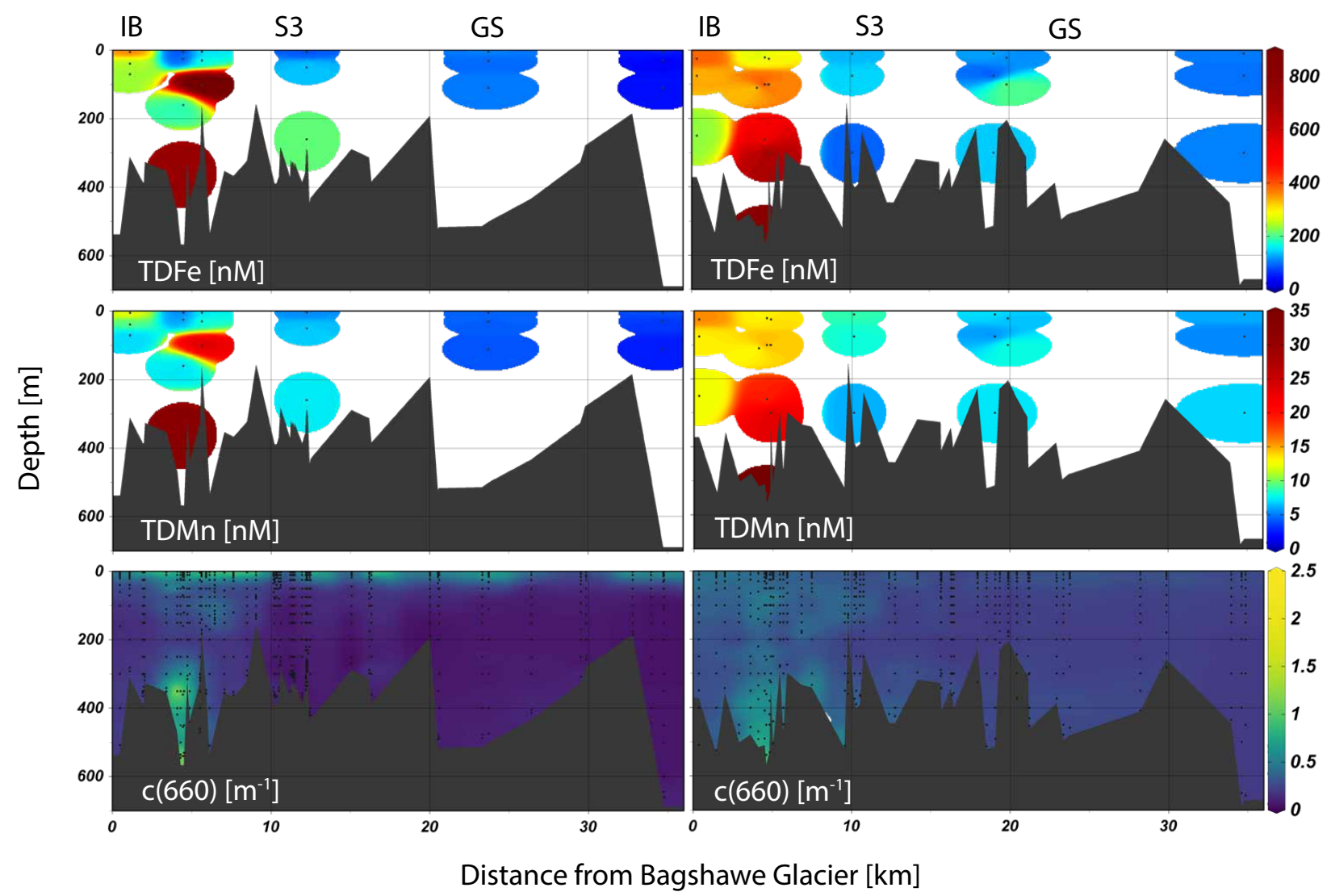

Figure 6. Total dissolvable trace metals and beam attenuation coefficient $\mathbf{c}(660)$ for both seasons. The transects are plotted as distance from the Bagshawe Glacier terminus. 

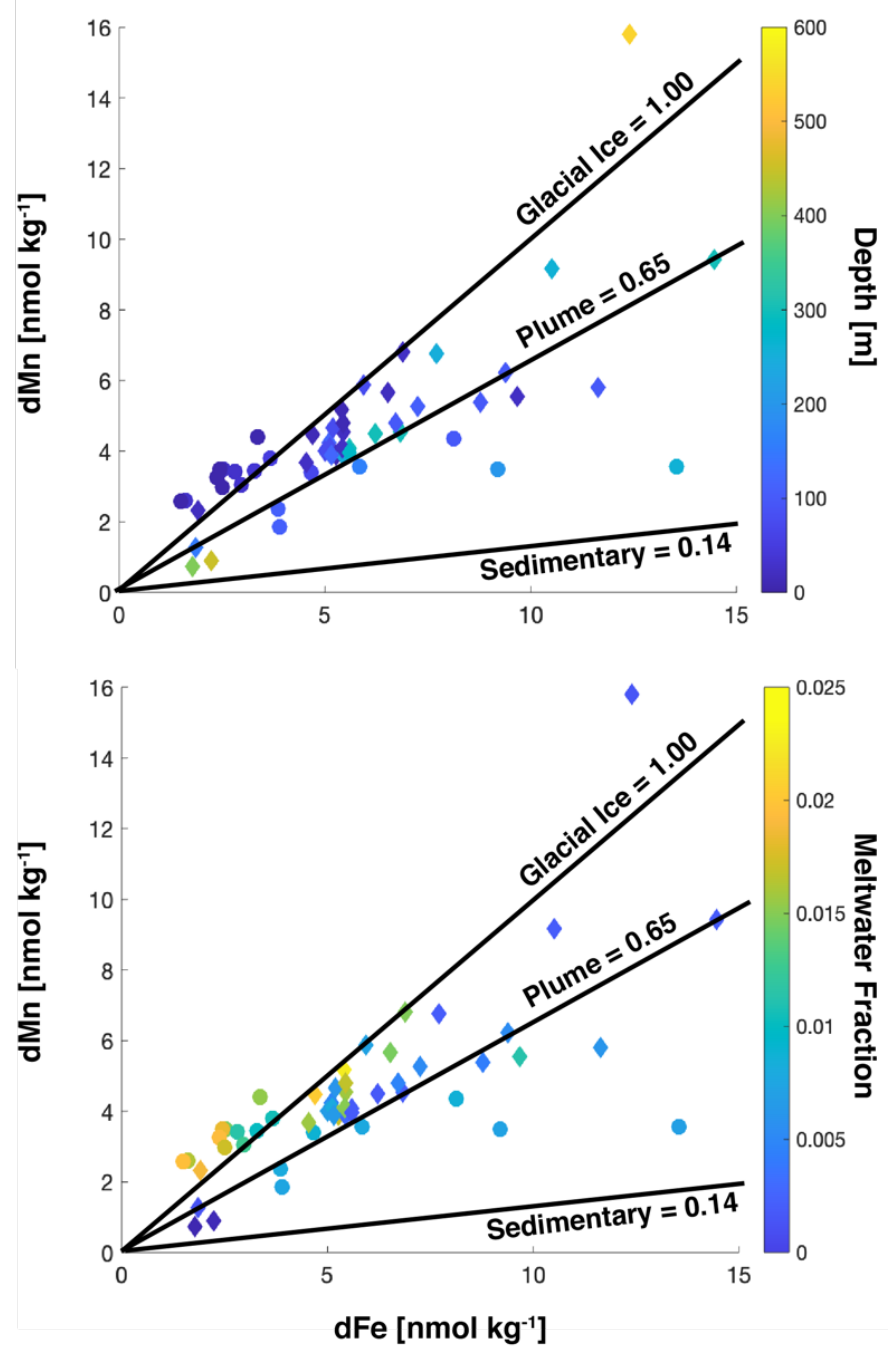

1045 Figure 7. Dissolved Fe and Mn plotted for water column samples. The colorbar shows depth (top panel) or meltwater fraction (bottom panel). For both panels, December 2015 cruise is indicated by filled circles and the April 2016 cruise is indicated by filled diamonds. The lines indicate the average Mn:Fe ratio for each candidate source. 

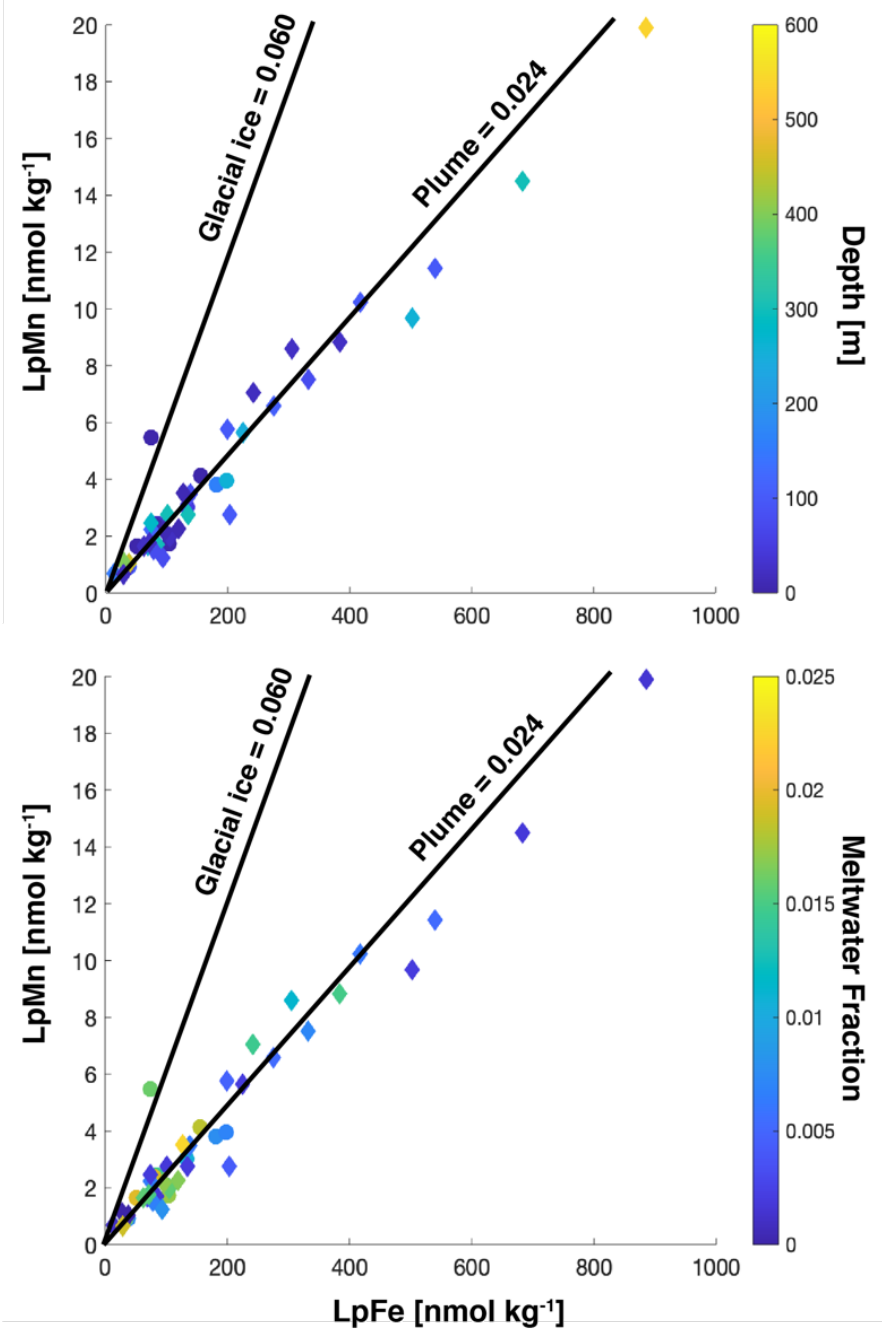

Figure 8. Labile particulate Fe and Mn plotted for water column samples. The colorbar shows the influence of depth (top panel) or meltwater fraction (bottom panel). For both panels, December 2015 cruise is indicated by filled circles and the April 2016 cruise is indicated by filled diamonds. The lines indicate the average ratio of $\mathrm{Mn}$ :Fe determined from candidate sources. 

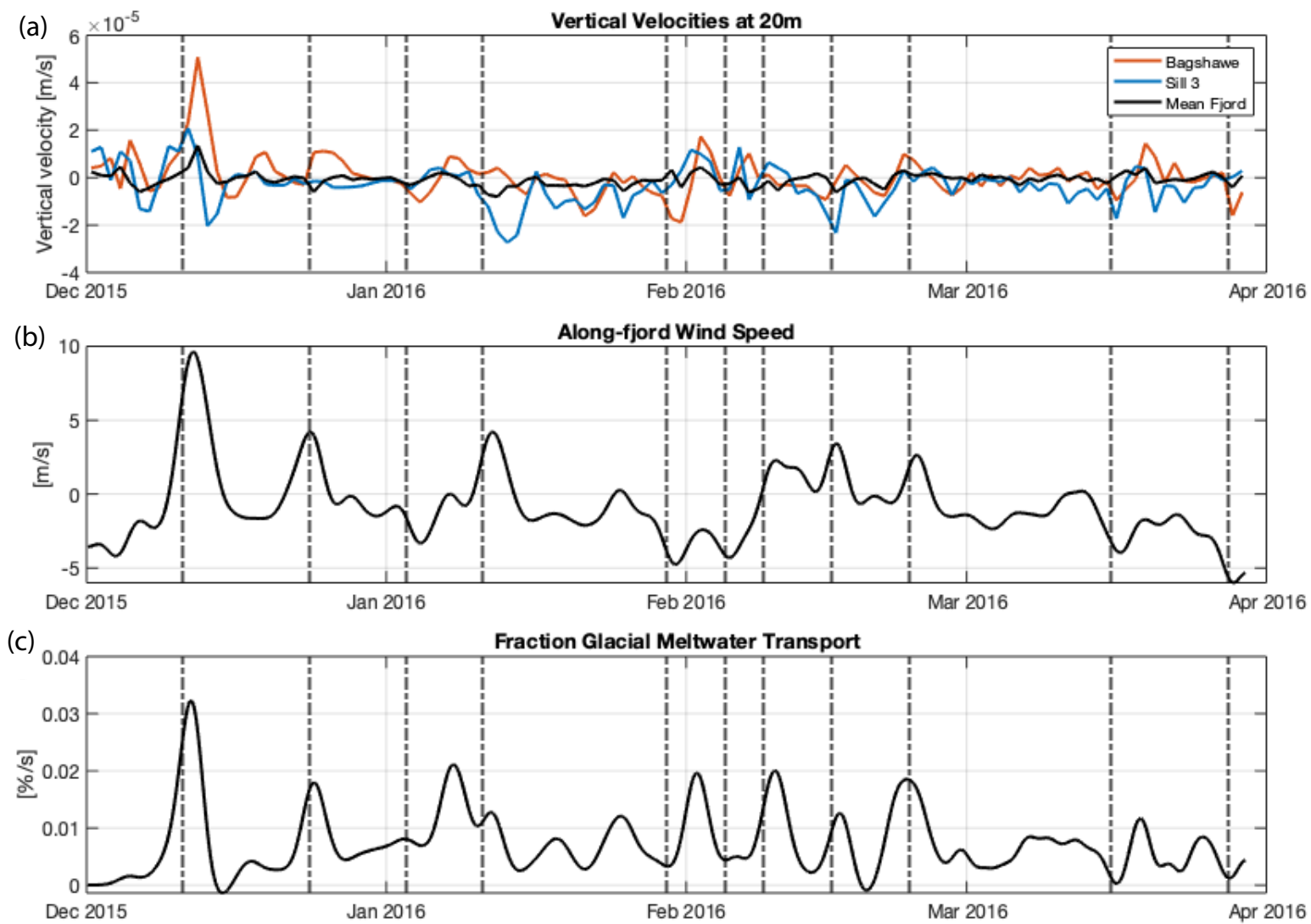

Figure 9. (a) Modelled vertical velocities at $20 \mathrm{~m}$ for the following locations: Bagshawe Glacier (IBA), Sill 3 and the fjord region average. 24-hr gaussian filter applied to time series of along-fjord wind velocity (b) and relative meltwater export out of the fjord (c). Wind events exceeding an absolute velocity of $8 \mathrm{~m} \mathrm{~s}^{-1}$ are indicated by vertical dashed lines. Wind speed data is based on biascorrected RACMO model output for the center of the fjord, used to force the ROMS model. The transport of meltwater dye is shown relative to the total amount of meltwater dye within Andvord Bay to focus on the physical dynamics and not the changes in volume of dye present in the fjord. 


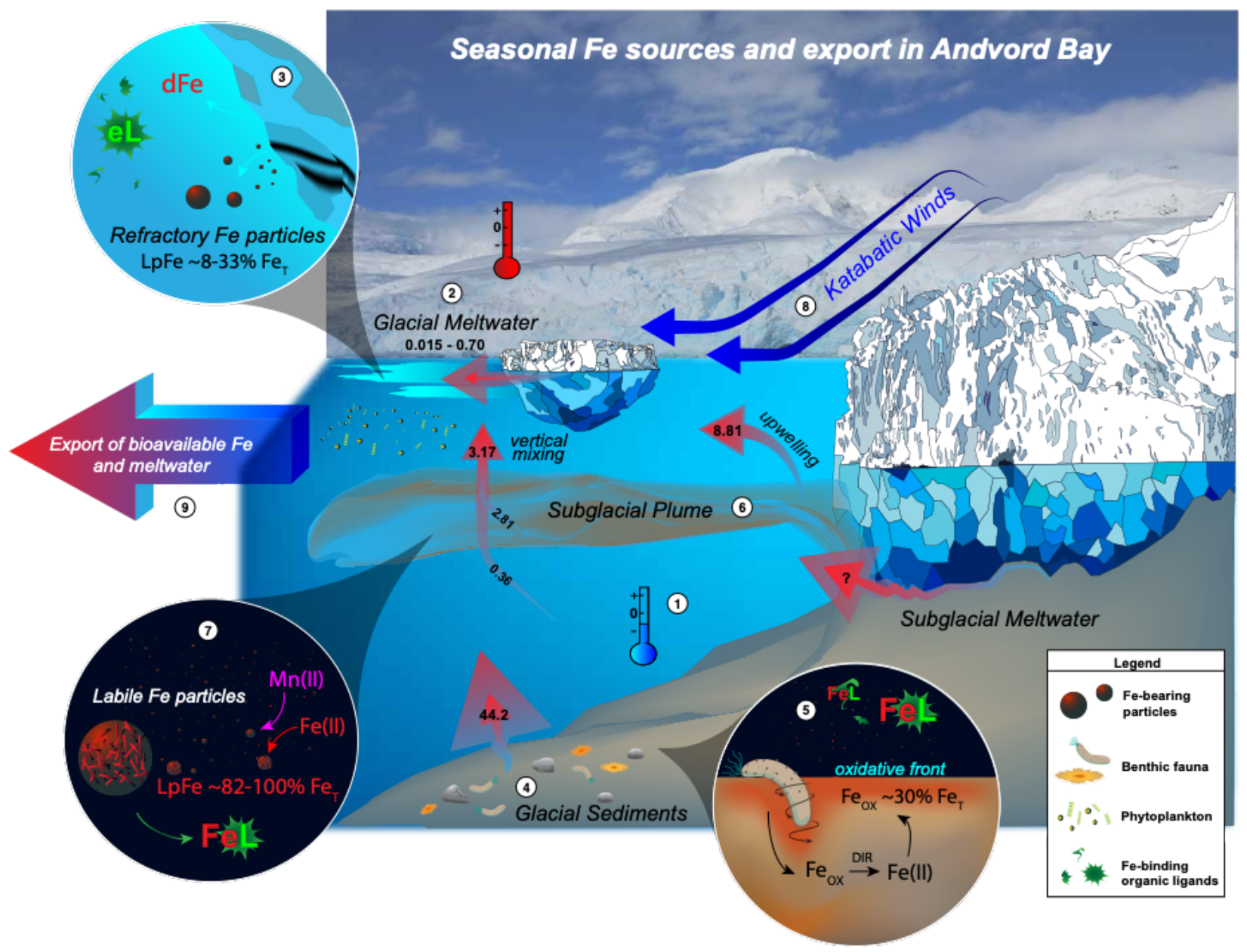

1060 Figure 10. Conceptual diagram showing the important seasonal sources of new Fe during the growth and melt season. The red arrows indicate the major fluxes (in $\left[\mu \mathrm{M} \mathrm{m}^{-2} \mathrm{~d}^{-1}\right]$ ), with the size ranges showing the uncertainty in the measurement - some fluxes are difficult to quantify. These fluxes also vary from season to season and from location to location and may even be going through long-term changes due to human influences, such as climate change, though this is not shown here. The small arrows show internal transformations of $\mathrm{Fe}$, which play an important role in the supply of Fe to phytoplankton. See text for a description of important processes highlighted by circled numbers. 


\section{Supplementary Material}

\section{Supplemental Methods: Estimating total meltwater export from WAP fjords}

In order to estimate the meltwater export resulting from a single katabatic wind event along the WAP, we first identify two fjord types: 1) fjords where waters are below the freezing temperature (cold-based); and 2) fjords where intrusions of modified UCDW reach the glacier terminus and cause melting. This distinction leads to different MWf production rates. We use data collected from Andvord Bay as a basis for the amount of export occurring in cold-based fjords. In this instance, a maximum MWf or 0.025 was observed, which corresponded to an export of $38 \times 10^{7} \mathrm{~m}^{3}$ glacial meltwater and is based on the glacial meltwater dye export across the mouth of Andvord Bay integrated over the duration of a week-long katabatic wind event.

Meltwater runoff from glaciers due to warm atmospheric temperatures is parameterized as a function of number of days above a temperature threshold (Smith et al. 1998). The area of the glacier in contact with the atmosphere predicts how much meltwater is generated. We use this simple relationship with surface area and relate it to the MWf we observe, allowing us to estimate the fractional contribution from each glacier in Andvord Bay. As an example, Bagshawe Glacier has an area of $250 \mathrm{~km}^{2}$, which is $48 \%$ of the total glacier area for this fjord, and so would be responsible for producing $48 \%$ of the surface glacial meltwater $\left(\sim 18.4 \times 10^{7} \mathrm{~m}^{3}\right)$. By dividing the total surface glacial meltwater export for a single katabatic wind event by the total area of glaciers in Andvord Bay, we calculate the export rate of meltwater in Andvord Bay glaciers to be $7.4 \times 10^{5} \mathrm{~m}^{3}$ $\mathrm{km}^{-2}$ assuming glaciers have an equal rate of meltwater production per unit area. We use this rate as representative for coldbased type glaciers.

Since warm atmospheric temperatures in contact with the glacier surface cause production of meltwater, which enters the ocean as surface runoff, this seems a reasonable assumption. Additionally, intrusions of modified UCDW can reach the glacier terminus, causing slightly higher fractions of meltwater at the surface $(\sim 0.06$ in Barilari Bay). Our general model results showed exchange with water outside of the fjord occurred during katabatic wind events, including inflow of water masses at depth located from outside of the fjord. Thus, these events are likely to enhance delivery of modified UCDW to the glacier terminus (Jackson et al. 2014). We scale the meltwater export to the meltwater fraction since both Barilari and Andvord Bays

1095 had similar mixed layer depths. Also, $40 \%$ export of meltwater during katabatic wind events in our model is reasonable compared to estimates for Arctic fjords (10-50\%, Jackson et al. 2014). Based on the area of glaciers in Barilari, we calculate an export rate of meltwater for representative warm-based glaciers to be $10.2 \times 10^{5} \mathrm{~m}^{3} \mathrm{~km}^{-2}$. We extrapolate these rough estimates for all glaciers on the western coast of the WAP identified by Cook et al. (2016). All glaciers to the south of Andvord Bay are considered warm-based, while those to the north are cold-based (SI Fig. 8). The area of each of the glaciers used here $\lfloor 100$ is published in Cook et al. (2016).

Summing the entire volume export of surface glacial meltwater, we find that if all surface waters along the western coast of the WAP experienced a single katabatic wind event, reminiscent of the one recorded in Andvord Bay, a total of $3.6 \mathrm{x}$ $10^{10} \mathrm{~m}^{3}\left(36 \mathrm{~km}^{3}\right)$ of surface glacial meltwater is exported towards the continental shelf $\left(5 \mathrm{~km}^{3}\right.$ from cold-based glaciers; 31 
$\mathrm{km}^{3}$ from warm-based glaciers). This latitudinal difference is consistent with greater meltwater fractions found on the continental shelf in the southern lines of the PAL LTER grid (Annett et al. 2017). Based on a recent compilation of TDFe content in icebergs from Antarctica (Hopwood et al. 2019), and including two measurements from our study, we use a median concentration of $544 \mathrm{nM}(n=57)$. We then assume a conservative solubility of $10 \%$ of TDFe as the dissolved phase, which yields a dFe content of glacial meltwater to be $54.4 \mathrm{nM}$. This is close to our average dFe measured for three glacial ice pieces in this study $(\sim 71 \mathrm{nM})$. We estimate a single wind event lasting one week on the western coast of the WAP corresponds to an export of $2.0 \times 10^{6} \mathrm{~mol} \mathrm{dFe}$.

We realize this analysis does not take in to account the impact of shallow sills in fjords that might be important for restricting UCDW from entering the fjord mouth and interacting with glaciers. Invigorated upwelling due to buoyant plumes originating at the glacier face is expected to have a positive feedback on the melting of the glacier terminus by increasing the delivery of modified UCDW to glaciers and enhancing melt (Cape et al. 2019). This may be driven by warm ocean

$\lfloor 115$ temperatures, directly melting the face of the glaciers, or atmospheric warming could increase drainage of surface melt to the base of the glacier, resulting in subglacial discharge and buoyant plumes driving circulation. Directionality of the katabatic winds is an important parameter for wind forcing in fjords surrounded by steep topographic features (Lundesgaard et al. 2018). We have explored the possibility when one katabatic wind event per year occurs in the along-fjord direction (seaward) for the entire western coast of the WAP. These mechanisms are fjord specific and deserve further attention due to the complex interactions between the ice, ocean, and atmosphere. We also concede that areal extent of glaciers may not be the most representative measure for meltwater production, when in fact glacier flow velocities might better correlate with meltwater production rates, and thus, meltwater export rates. However, the interplay between surface melt and the subglacial hydrological system, and thus flow rates could mean this is a sufficient, albeit rough assumption. Finally, large uncertainties exist for the average glacial ice content of $\mathrm{dFe}$ and the degree to which TDFe may be solubilized and made bioavailable. This analysis does not take into account the large quantities of solid ice (i.e., icebergs) exported via this mechanism. 


\section{Supplemental Figures and Tables}

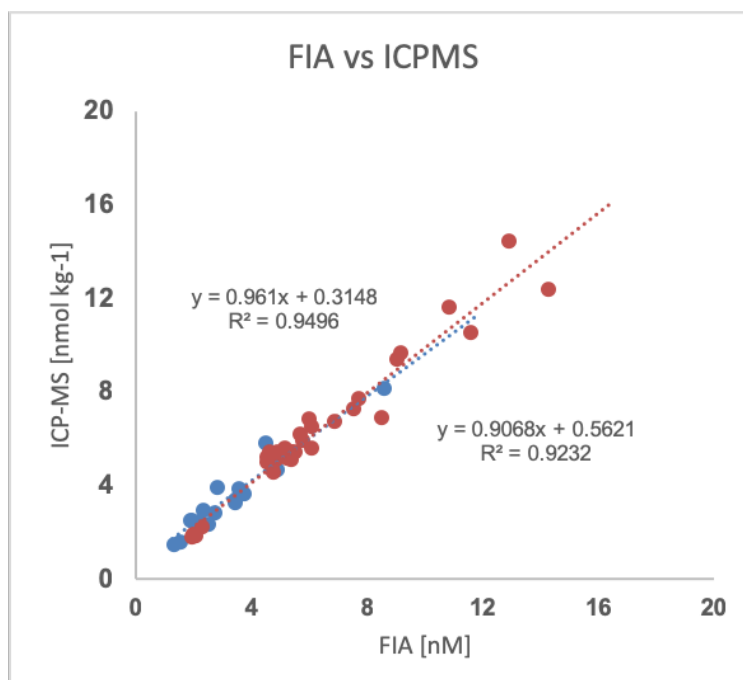

SI Figure 1. Comparison of analytical detection methods used for the determination of dissolved Fe (FIA versus ICP-MS). The red line denotes the 1:1.
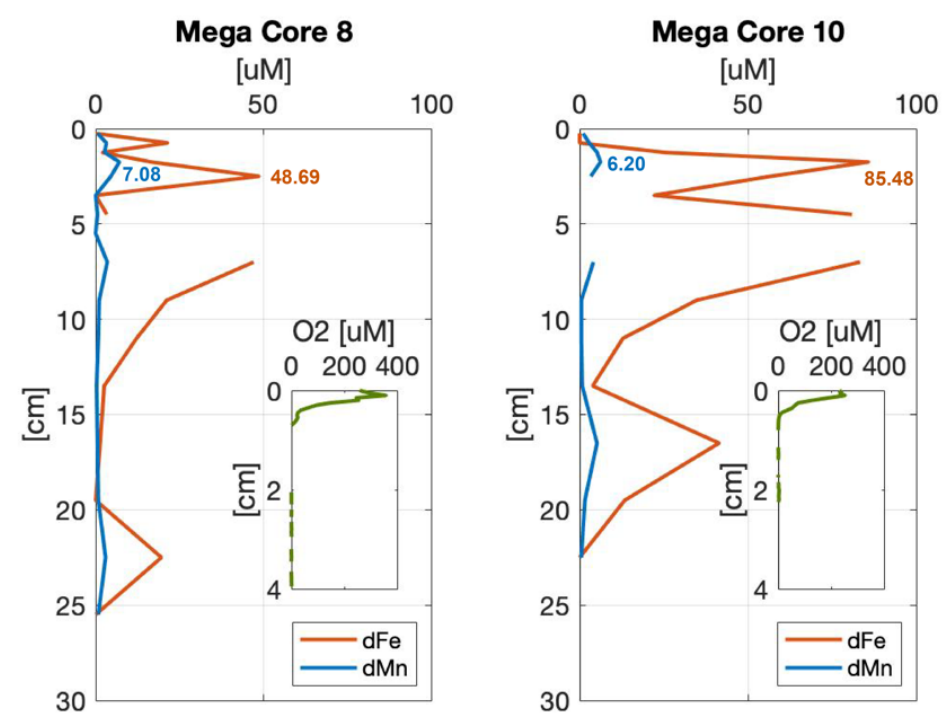

$\lfloor 130$

SI Figure 2. Porewater dissolved metal concentrations for Fe (red), manganese (blue), and oxygen (green) for Mega Core 8 (left) and 10 (right), at the coring station near OB (see Fig. 1). 


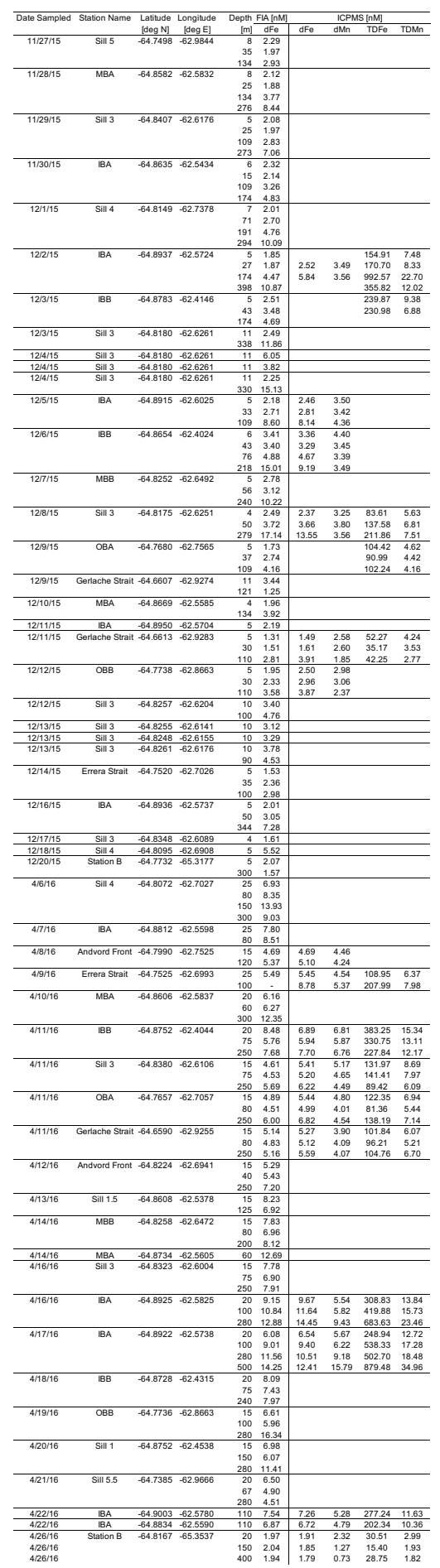

L135 SI Table 1. Seawater samples: Fe, Mn determined for the dissolved (dTM, $0.2 \mu \mathrm{m})$ and the total dissolvable (TDTM) determined by FIA and ICPMS methods, and collected during LMG1510 and NBP1604. Additional information covers sampling date, location (station), and latitude and longitude. 

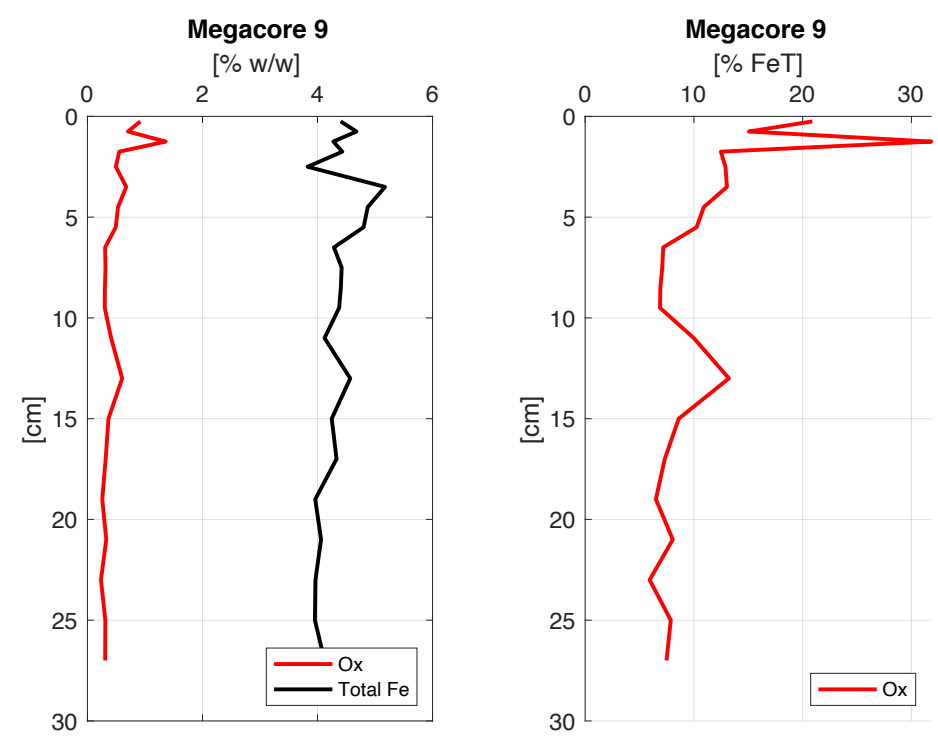

SI Figure 3. Speciation of Andvord Bay sediments as percent dry sediment weight (left) and percent total Fe (right) for defined fractions based on chemical lability, as in Burdige et al. 2020. Ox = oxides.
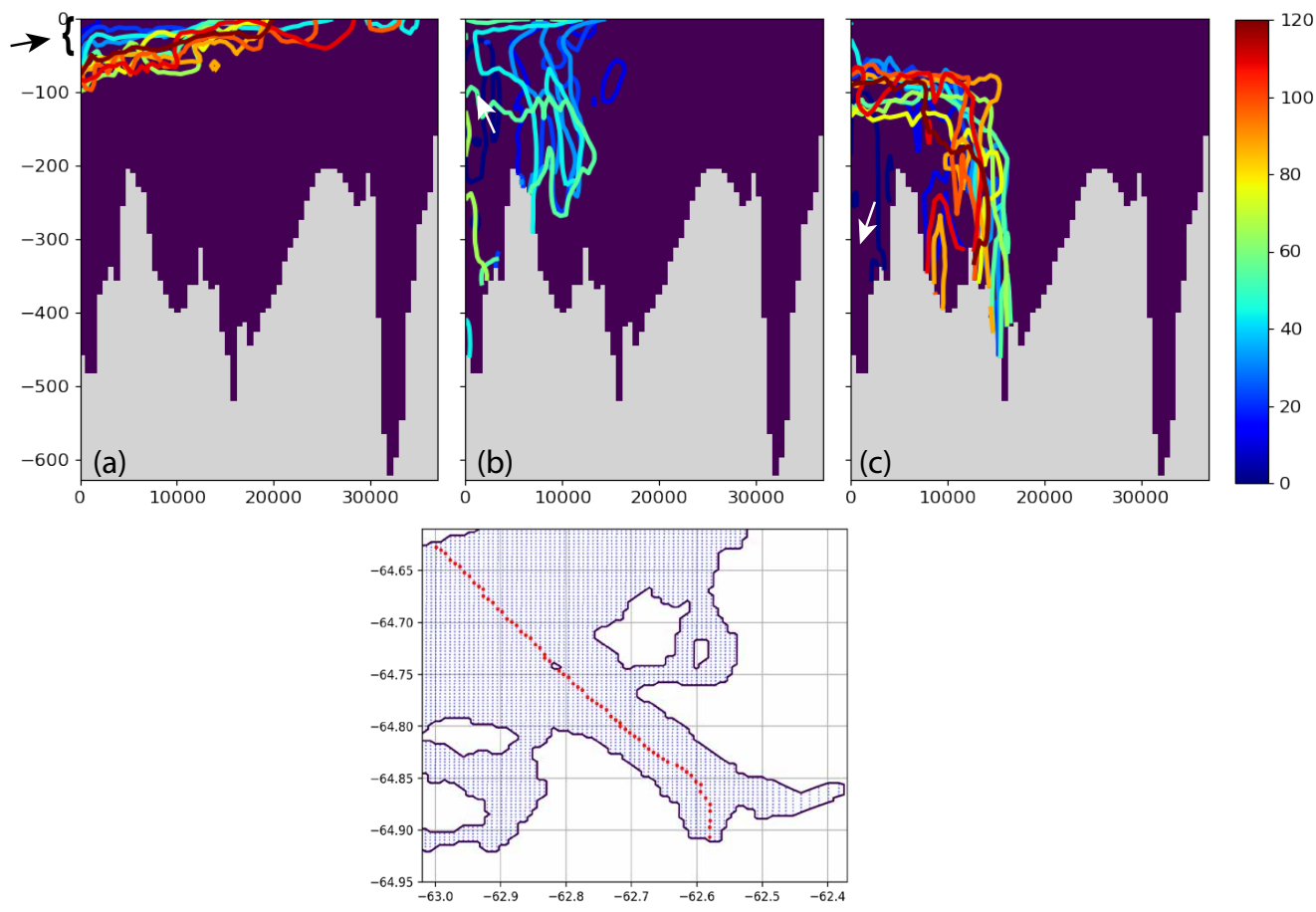

SI Figure 4. Modelled fate of numerical dyes representing three possible Fe sources. Contours show the $0.1 \%$ extent for the (a) meltwater dye and the $0.01 \%$ extent of the (b) subsurface, and (c) deep dyes according to the day in the model run (colorbar). Approximate dye release depth and location are highlighted by the arrows. The plots are oriented from the inner basins $(0 \mathrm{~m})$ to the Gerlache Strait $(\sim 35000 \mathrm{~m})$ as distance from Bagshawe Glacier ([m]). 


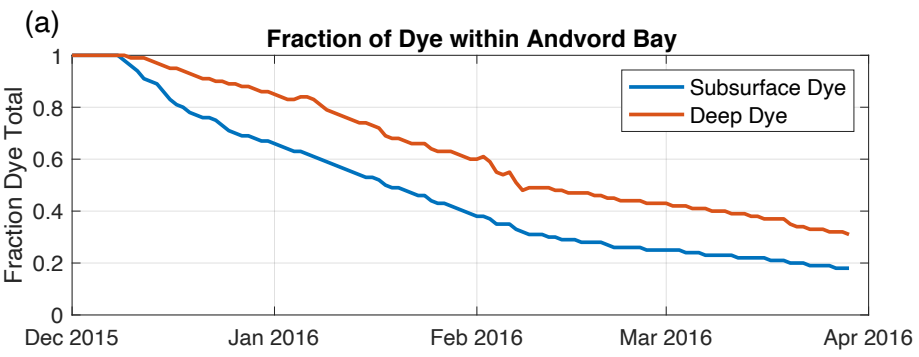

(b)

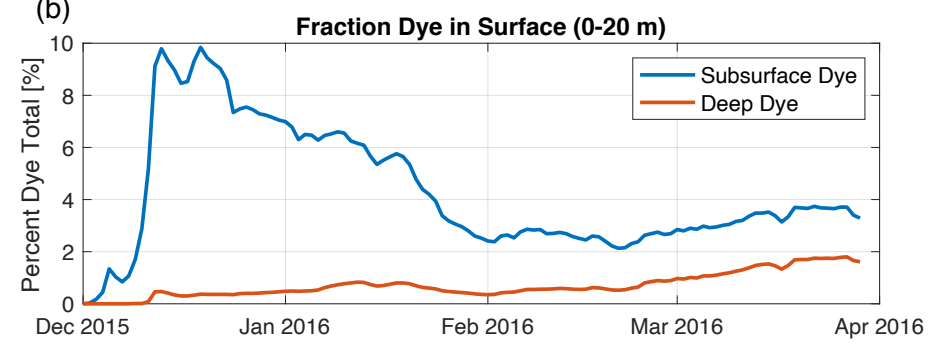

SI Figure 5. (a) Fraction of initial subsurface (blue) and deep (orange) numerical dye within the fjord domain over the 120-day model run. (b) Percentage of subsurface and deep dye within the surface layer $(0-20 \mathrm{~m})$ over the 120-day model run.

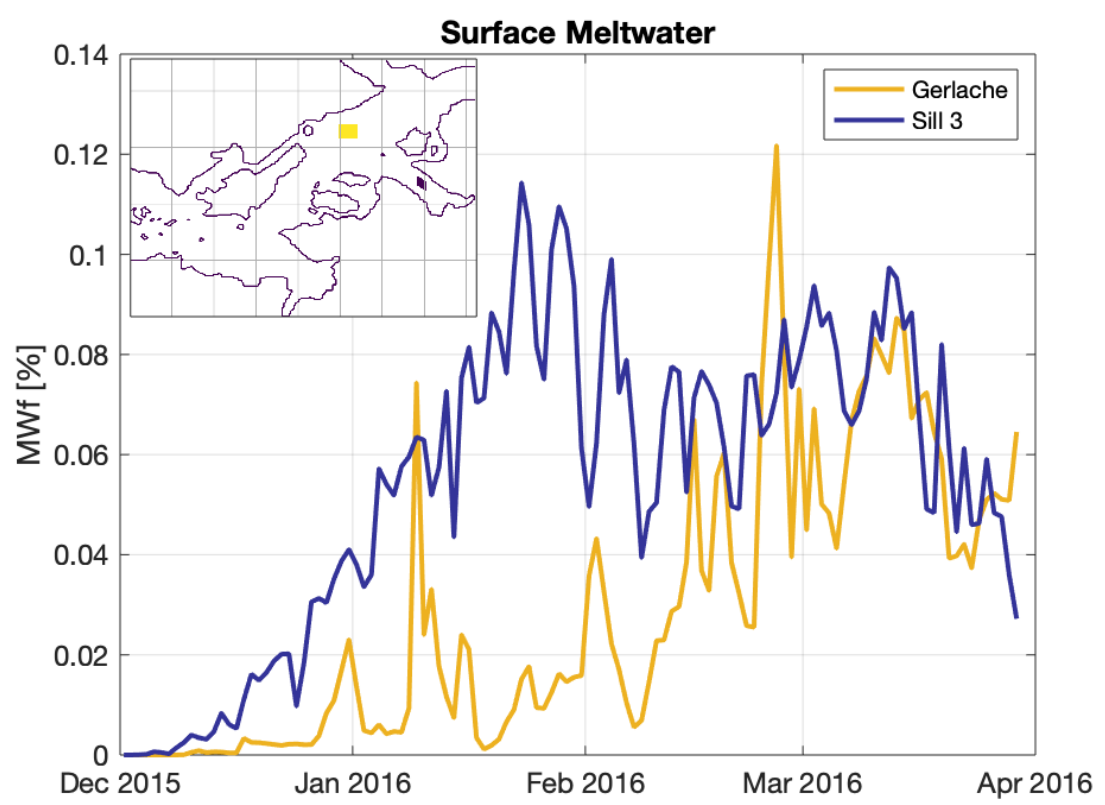

SI Figure 6. Modelled surface $(0-20 \mathrm{~m})$ meltwater fraction for Gerlache Strait and Sill 3 (map inset), over the course of the 2015-16 summer season. 

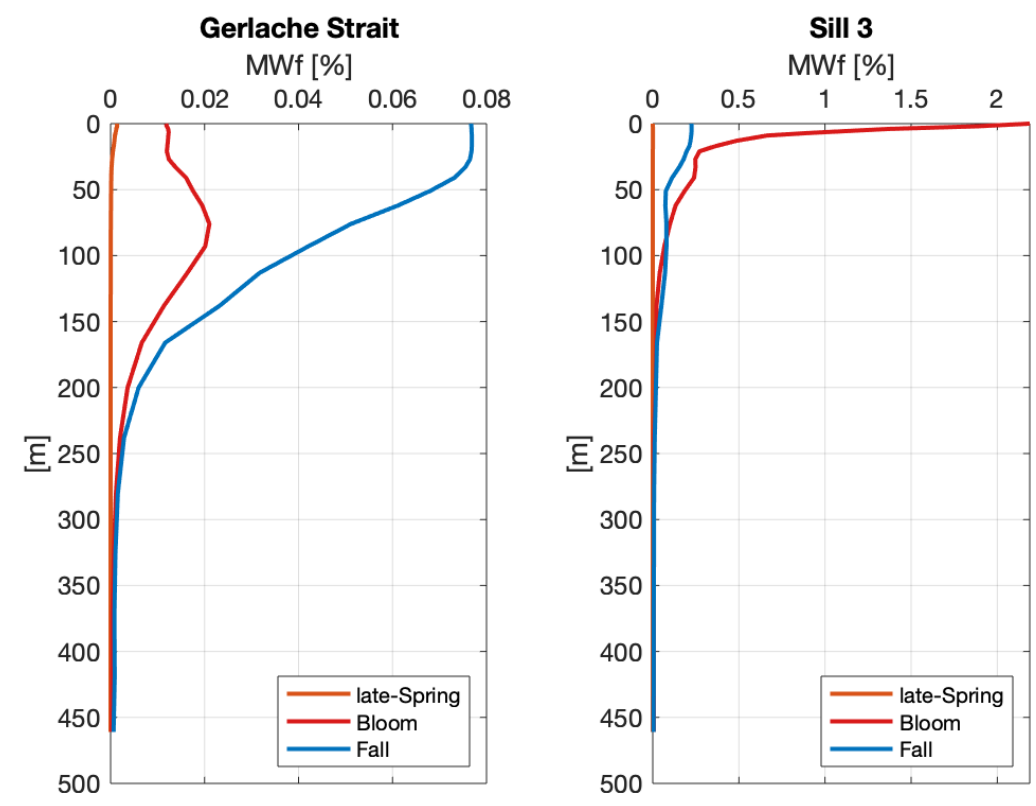

SI Figure 7. Modelled meltwater dye profiles as a percent of water volume in the (left) Gerlache Strait and (right) Sill 3. Each profile corresponds to a different timepoint: late-Spring (December 11, 2015 Gerlache, December 3, 2015 Sill 3), peak bloom period (January 27, 2016), and simulation end (March 29, 2016). Note the different $x$-scales. 


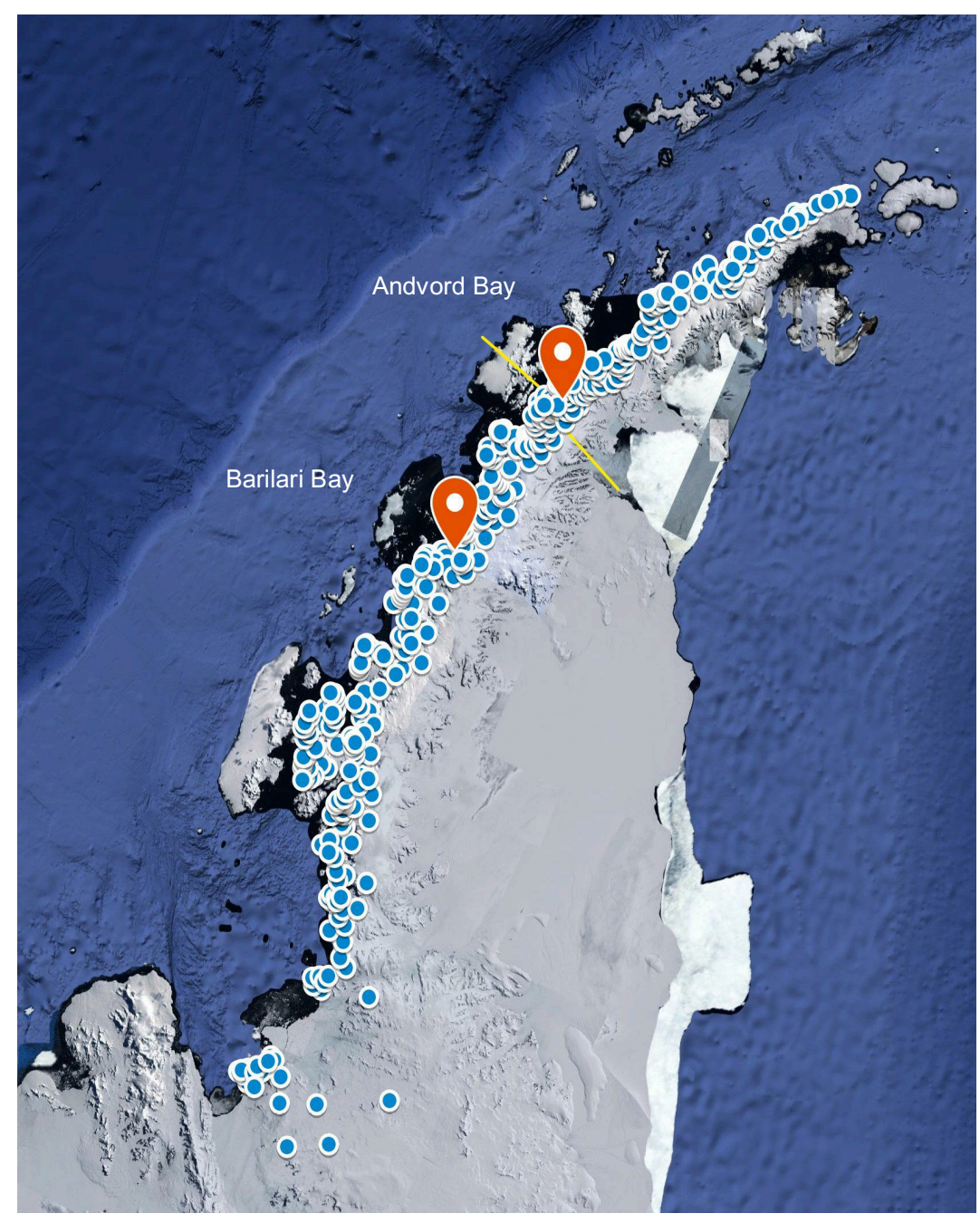

SI Figure 8. Map showing all 432 glaciers (blue dots) located on the western coast of the WAP (from Cook et al. (2016)). The $\lfloor 160$ yellow line indicates the region of convergence of two intermediate water masses; cold Weddell Water to the north and warm modified UCDW to the south. Image was $p$ 